\title{
Adversity-hope hypothesis: Air pollution raises lottery demand in China
}

\author{
Soo Hong Chew ${ }^{1,2} \cdot$ Haoming $\mathrm{Liu}^{2,3} \cdot$ Alberto Salvo $^{2}$
}

Accepted: 1 July 2021 / Published online: 13 August 2021

(C) The Author(s) 2021

\begin{abstract}
The empirical literature points to a stylized phenomenon of increased demand for hope following adversity. Clotfelter and Cook (1989) suggest that hope is a key sentiment underpinning recreational gambling. Chew and Ho (1994, this journal) offer the view of hope being experienced in lottery products when people enjoy delaying the resolution of uncertainty. Taking air quality as an indicator of subjective wellbeing, we hypothesize a positive causal relationship between air pollution and lottery sales. We test this hypothesis using data from China and find that air pollution measured by particle concentration increases demand for a popular lottery for which province-level daily sales records exist. The relationship can readily be seen on combining high-frequency, spatially resolved lottery sales and particle pollution data. Our findings support the adversity-hope hypothesis in the context of air quality and lottery sales and point to further tests using other measures of adversity and proxies of demand for hope.
\end{abstract}

Keywords Adversity $\cdot$ Hope $\cdot$ Attitudes toward risk and hope $\cdot$ Environmental degradation $\cdot$ Air pollution $\cdot$ Lottery demand $\cdot$ Particulate matter $\cdot$ Haze $\cdot$ Smog . Instrumental variables

JEL Classification D12 · D91 · D81 · G41 · H23 · L83 · Q51 · Q53

"The heart that is well prepared for any fate hopes in adversity and fears in prosperity."

-Horace, 65-8 BC

"It is principally at games of chance that a multitude of illusions support hope and sustain it against unfavorable chances."

-Laplace, A Philosophical Essay on Probabilities, 1796/1902

Haoming Liu

ecsliuhm@nus.edu.sg

Extended author information available on the last page of the article. 


\section{Introduction}

Risk taking underpins much of the economic activity in any modern society. At one extreme of the risk-taking spectrum lies financial investment, which is deliberate, consequential, and focused especially in the capital markets. At the other extreme, we have recreational risk taking and gambling which tend to be impulsive, low-stake, augmented by non-conscious cues and insensitivity to the inherently unfavorable odds. The perception of risk ranges from being a necessary evil to be tamed and managed in financial risk taking to an object of fun and entertainment to be enjoyed in moderation in recreational risk taking. Apart from pathological gamblers, recreational risk takers tend to be conscious of the prospect of losing while they enjoy gaming activities in the hope of winning, as prefaced by the quotation from Laplace in the epigraph.

Recreational gambling such as participating in lotteries has been part and parcel of human societies since time immemorial. In Selling Hope, Clotfelter and Cook (1989) argue that lottery products, characterized by small chances of sizable winnings at low prices, fulfill a demand for hope often by those of lower socioeconomic status. On the supply side, the state lottery has been viewed as a form of regressive taxation (Price \& Novak, 1999). Earlier attempts to modeling a demand for lottery products in various non-expected utility models center around a sense of optimism arising from the overweighting of small winning probabilities. From this perspective, Chark et al. (2020) investigate the popular approach to modeling optimism using a probability weighting function directly as in Kahneman and Tversky (1979), and alternatively by applying an outcome-based salience function based on Chew (1983). Intuitively, optimism may underpin the consumer's hope to win despite unfavorable odds (Lopes, 1987).

Chew and Ho (1994, this journal, henceforth CH94) and Lovallo and Kahneman (2000) offer a novel strand of thinking of hope as a sentiment underpinning lottery demand, in which individuals enjoy delaying the resolution of uncertainty. CH94 provide preference specifications that capture a hope-induced utility for preferring later resolution of uncertainty. For some lottery products, such as New York State's Instant Scratch-off, the lottery outcome can be resolved immediately after purchase. Most other lottery products involve some delay between the time of purchase and the drawing of winning outcomes. A popular form of gambling in mainland China today is the daily three-digit lottery (3D). A 3D ticket costs CNY 2 and pays CNY 1,000 if the three digits picked by a bettor are drawn during the live broadcast on national TV the evening of purchase. ${ }^{1}$ On average 21 million 3D lottery tickets are sold daily by China's Welfare Lottery authority, equivalent to about 2 daily bets for every 100 persons aged 16 years and above.

The empirical literature points to a stylized phenomenon of an increase in demand for hope following adversity, for instance, during economic downturns or after natural disasters. This is corroborated by studies that find a positive relation between economic hardship and gambling or lottery purchases. Mikesell (1994) discusses

\footnotetext{
${ }^{1}$ The winning odds are $1 / 1000$. One US dollar is equivalent to about 6.5 Chinese yuan (CNY).
} 
the positive relationship between state unemployment and lottery sales in the US. Olason et al. (2017) find an increase in gambling participation but not problem gambling after the 2008 economic collapse in Iceland. Writing in the aftermath of the Great Recession, Zezima (2008) notes that "sweet dreams in hard times add to lottery sales." In the wake of heavy snow and an earthquake in China in 2008, Li et al. (2011) report increased lottery demand (a $0.1 \%$ chance to win CNY 10,000 at a price of CNY 10) in affected vs. non-affected areas. ${ }^{2}$ Isidore (2017) reports on the "billions of dollars [that] go unclaimed in lottery prizes" pointing out that some people may even not bother to check if they won. For such consumers, the hope component of a lottery itself may be worth the ticket price.

We are led to posit an "adversity-hope hypothesis," as prefaced by Horace in the epigraph, with lottery sales serving as a proxy for hope. To test this hypothesis, we examine a routine source of moderate-level adversity in the form of environmental pollution. Particles in ambient air-that contribute to haze or smog — are arguably the most visible time-varying manifestation of environmental pollution in developing countries, including China (Lelieveld et al., 2015; Marlier et al., 2016). When it is visible, this form of environmental degradation can affect a healthy human not only through inhalation but also through perception (Watson, 2002; Zhang et al., 2015). It is hard to miss a hazy vs. blue-sky day in Beijing, Delhi, or Jakarta even if one is able to stay inside, behind windows that properly shut. Recent papers have also documented the acute effect of air pollution on subjective well-being (Levinson, 2012; Zhang et al., 2017; Zheng et al., 2019). In this context of air pollution, our adversity-hope hypothesis would entail an increase in lottery ticket sales when air quality declines - with the mechanism being a preference for later resolution of uncertainty but not optimism.

We examine a possible relation between air quality proxied by PM2.5 (particulate matter up to $2.5 \mu \mathrm{m}$ in diameter) and daily sales of the 3D lottery which is generally purchased during the day and is drawn at $9 \mathrm{pm}$. The fixed-prize-fixed-odds nature of the 3D lottery, paying CNY 1,000 at 1/1000 winning odds and for which we have daily provincial-level sales data over multiple years is ideal for our investigation. We find evidence that is compatible with the adversity-hope hypothesis. Controlling for month-of-sample, day-of-week, and weather, flexibly by province, 3D betting rises and falls in step with PM2.5 (haze) pollution. The positive causal relationship that we document can readily be seen in Fig. 1 on combining the high-frequency, spatially resolved lottery sales and PM2.5 records.

We provide regression evidence based on alternative identifying assumptions. Studies of the socioeconomic impact of pollution need to contend with the possibility that pollution is associated with unobserved day-to-day variation in economic activity. For instance, high-frequency shifts in labor demand and changes in daily wages could directly impact lottery sales. For this reason, one estimator we implement focuses on air quality variation attributable to naturally and exogenously occurring

\footnotetext{
${ }^{2}$ In the context of a major earthquake in New Zealand, Sibley and Bulbulia (2012) provide evidence that secular people turn to religion at times of crisis. North et al. (2005) document that residents of Nairobi, Kenya relied on religious support after terrorist bombings.
} 


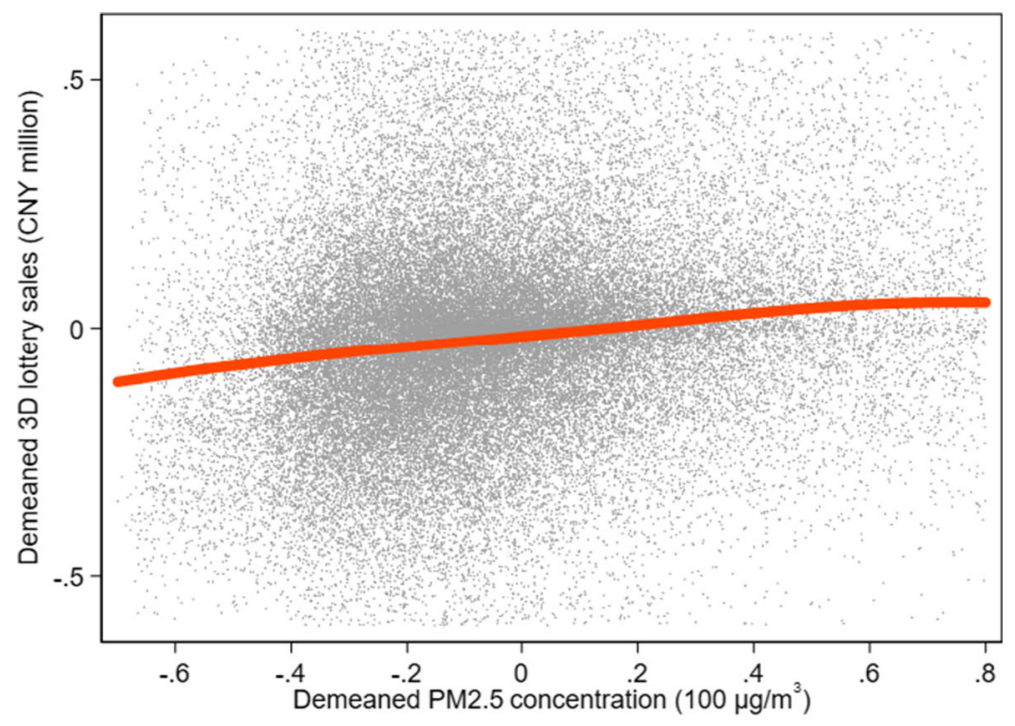

(a) 3D lottery sales (CNY million, demeaned)

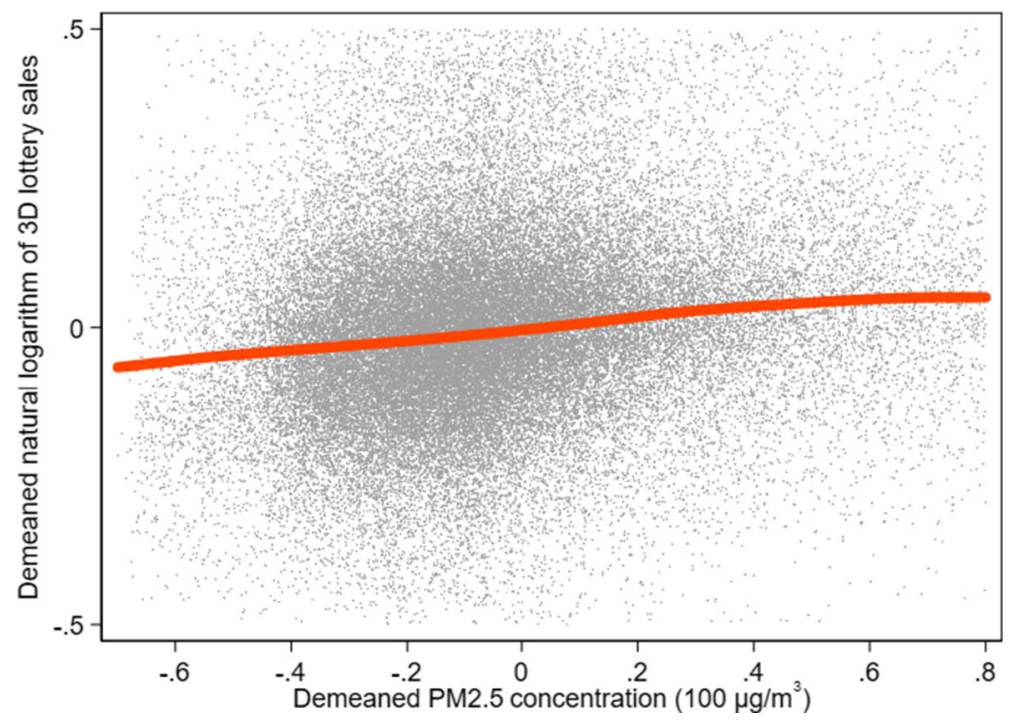

(b) Log of 3D lottery sales (demeaned)

Fig. 1 Demeaned 3D lottery sales against demeaned daytime PM2.5, after subtracting province-level means. An observation is a province by day in the five years from 2013 to 2017 . There are 32 provinces in the data. The top panel shows sales in CNY million, the bottom panel reports the natural logarithm of sales. For better visualization, we include locally weighted polynomials of best fit and omit a few outlying realizations (e.g., percentiles 1 and 99 of the distribution of demeaned $\log 3 \mathrm{D}$ sales are -0.6 and 0.7 ) 
shifts in atmospheric regime ("thermal inversions"). We are then able to rule out economic activity as a candidate explanation for the positive relationship between lottery sales and pollution, which is co-produced with economic activity.

We further find that, fixing a day's average pollution dose, daily 3D sales are higher when the pollution dose is allocated toward the morning and away from the afternoon. This is consistent with the expectation sense of hope since morning purchases deliver more time for the consumption of hope in a lottery ticket purchase prior to its resolution in the evening.

The empirical analysis in this paper supports the adversity-hope hypothesis with air quality shifting hope attitudes. Our paper contributes to a recent literature documenting the acute impacts of air pollution on socioeconomic outcomes. These include cognitive performance (Zhang et al., 2018; Archsmith et al., 2018), self-reported happiness and subjective well-being (Levinson, 2012; Zhang et al., 2017; Zheng et al., 2019), individual investor activity (Meyer \& Pagel, 2017; Li et al., 2017), decisionmaking (Chew et al., 2021), test scores (Ham et al., 2014; Ebenstein et al., 2016; Graff Zivin et al., 2020), and crime and unethical behavior (Lu et al. 2018; Herrnstadt et al. 2019, 2021). ${ }^{3}$

In the next section, we posit the adversity-hope hypothesis. Section 3 tests the adversity-hope hypothesis in the setting of daily lottery sales and an environment with routinely high and exogenously varying air pollution in China. We present the institutional setting, show evidence of a relationship in the raw data, and implement empirical models of lottery demand that seek to establish both internal and external validity. Section 4 summarizes and provides a discussion.

\section{Adversity-hope hypothesis}

To model the adversity-hope hypothesis exposited in the Introduction, we apply the CH94 model about hope being experienced "when there is enjoyment in delaying the resolution of uncertainty." A lottery ticket typically involves a future period at which the final uncertainty is resolved. For such lotteries, attitude toward timing of uncertainty resolution has some bearing on the perceived attitude toward risk. Even if one is averse toward risks that resolve in the present period, one may still buy "hope" by purchasing a lottery ticket to enjoy the anticipation of winning.

We adopt the notation from $\mathrm{CH} 94$ in a two-period setting. Period-1 consumption is certain and is denoted by $y$ whereas the uncertain consumption in period 2 is denoted by $m=\sum q_{i}\left[z_{i}\right]$, a lottery which pays $z_{i}$ with probability $q_{i}$ (subscript $i$ denotes a realization). Together, these flows constitute a consumption plan $[y, m]$ in which $y$ is consumed in period 1 and lottery $m$ is consumed as period 2 begins but the consumer does not yet know which $z_{i}$ payoff she will receive until uncertainty is resolved.

The above $\sum q_{i}\left[z_{i}\right]$ notation has the advantage of enabling us to differentiate it from another case, denoted by $\sum q_{i}\left[y, z_{i}\right]$, in which uncertainty about period- 2 consumption $z_{i}$ is resolved early along with the certain period- 1 consumption $y$, i.e., the

\footnotetext{
${ }^{3}$ For a review of this cross-disciplinary literature, see Lu (2020).
} 
consumer already knows the specific $z_{i}$ payoff to be consumed in period 2 as period 1 begins. More generally, we refer to a temporal lottery, denoted by $\sum q_{i}\left[y_{i}, m_{i}\right]$, as a stochastic consumption plan $\left[y_{i}, m_{i}\right]$ which delivers the specific plan $\left[y_{i}, m_{i}\right]$ with probability $q_{i} .^{4}$

Let $M$ denote the set of temporal lotteries. Consider two alternative temporal lotteries, each involving consumption of $y$ in period 1:

$$
\alpha[y, m]+(1-\alpha)\left[y, m^{\prime}\right] \text { and }\left[y, \alpha m+(1-\alpha) m^{\prime}\right] .
$$

The LHS of (1) represents early resolution in period 1 of the period- 2 consumption that obtains-i.e., $m$ versus $m^{\prime}$, with probabilities $\alpha$ and $1-\alpha$. By contrast, in the RHS the uncertainty of period- 2 consumption resolves later. The enjoyment of hope corresponds to a preference for the temporal lottery described in the RHS of (1) rather than in the LHS.

We refer to a situation in which a consumer is indifferent between either temporal lottery, LHS vs. RHS irrespective of $\alpha, y, m$, and $m^{\prime}$, as one of timing indifference, following Kreps and Porteus (1978), which offers the following preference specification over temporal lotteries. Let $W$, called an aggregator (in the sense that it aggregates utility across periods), be a continuous and increasing function on $Y \times Y$. For instance, consider a simple form of the intertemporal aggregator function of consumption $y$ and $z$ in periods 1 and $2:^{5}$

$$
W(y, z)=v(y)+v(z),
$$

The recursive expected utility (REU) of a temporal lottery $d$ which yields $\left[y_{i}, m_{i}\right]$ with probability $q_{i}$ is given by:

$$
V(d)=\sum q_{i} W\left(y_{i}, \mu_{e}\left(m_{i}\right)\right)
$$

where $\mu_{e}(m)=u^{-1}(E[u, m])$ is the certainty equivalent of lottery $m$ under expected utility, i.e., accounting for the within-period aversion to risk under concave utility function $u$. As shown in CH94, an REU consumer is hopeful if $\left[y, \alpha m+(1-\alpha) m^{\prime}\right]$ is preferred to early resolution $\alpha[y, m]+(1-\alpha)\left[y, m^{\prime}\right]$ when the concavity of the $v$ function dominates and the composite $h=v \circ u^{-1}$ is concave, i.e.,

$$
\begin{aligned}
V([y, \alpha m & \left.\left.+(1-\alpha) m^{\prime}\right]\right)=v(y)+h\left(E\left[u, \alpha m+(1-\alpha) m^{\prime}\right]\right) \\
& =v(y)+h\left(\alpha E[u, m]+(1-\alpha) E\left[u, m^{\prime}\right]\right) \\
& >v(y)+\alpha h(E[u, m])+(1-\alpha) h\left(E\left[u, m^{\prime}\right]\right) \\
& =V\left(\alpha[y, m]+(1-\alpha)\left[y, m^{\prime}\right]\right)
\end{aligned}
$$

Note that standard discounted additive expected utility theory corresponds to the case of a linear $h$ function. This case necessarily satisfies timing indifference and cannot exhibit hopefulness. To capture our adversity-hope hypothesis, we posit that the hope

\footnotetext{
${ }^{4}$ In this general form the period-2 realization is itself a lottery $m_{i}$ rather than a specific outcome $z_{i}$.

${ }^{5}$ We omit the discount factor between period 1 and period 2 given the short duration of the uncertainty. In our empirical setting, a consumer can purchase a 3D lottery ticket during the day and resolve the uncertainty by the evening, when the winning numbers are announced. Some bettors may choose to learn of the winning numbers later, in subsequent days, as they have up to 60 days to collect any prize.
} 
function $h$ would become more concave at times of adversity. ${ }^{6}$ To induce a baseline demand for a state lottery, we can augment the above analysis by applying some level of probability overweighting through a non-expected utility (NEU) model, such as weighted utility (WU) or reference-dependent utility (RDU), of the certainty equivalent of the period-2 uncertainty (Chark et al., 2020). The hope function then plays a modulating role of the baseline demand through changes in its curvature.

In the next section, we test the implication of the CH94 hope model in the setting of air quality and daily sales of a fixed-prize-fixed-odds lottery in China. An adverse environment would tend to increase the value of a lottery ticket purchased in the morning whose outcome will be revealed in the evening, giving rise to greater demand for the lottery. Absent a hope channel, deteriorating air quality associated with increased risk aversion or reduced optimism might lower, rather than increase, lottery demand.

\section{Evidence from daily lottery sales}

\subsection{Institutional setting and data}

Gambling was banned in China from 1949, the year the People's Republic of China was founded, until 1984. That year, the Chinese Sports Association was allowed to offer betting on sporting events with the aim of funding the Beijing International Marathon. The following year, the State Council authorized the National Sports Commission to offer betting on a regular basis. In 1987, the Ministry of Civil Affairs was allowed to sell lottery products to fund social welfare and provide for public goods. Three decades later, the state-run Welfare Lottery and Sports Lottery authorities have similar revenue shares of China's regulated lottery duopoly (Betting Guide, 2018; AGTech, 2018). ${ }^{7}$

"Number picking" (hereafter, number) lotteries, supplied by the two nationallevel agencies, are the most popular accounting for $62 \%$ of lottery sales (Ministry of Finance, 2017). These consist of 3D, Double Color Balls, and Lotto 7 supplied by the Welfare Lottery, and PL3, PL5, Big Lotto, and Seven Stars from the Sports Lottery. The Double Color Balls, Lotto 7, Big Lotto, and Seven Stars run thrice weekly and have variable prizes that depend on whether there are rollovers from the preceding rounds. By contrast, the 3D, PL3, and PL5 have fixed winning prizes and are run daily.

Table 1 describes the sales data available for 32 areas, including 22 provinces, five Autonomous Regions, and five major cities, hereafter 32 provinces. ${ }^{8}$ Detailed daily sales data are publicly available for 3D for all 32 provinces. Sales for the other

\footnotetext{
${ }^{6}$ Suppose $v=x^{\rho}$ and $u=x^{\lambda}$ so that $h=x^{\rho / \lambda}$, then the hope parameter given by $\rho / \lambda$ would decrease with adversity.

${ }^{7} 2017$ official lottery sales were CNY 427 billion.

${ }^{8}$ The cities are the four officially designated Municipalities with provincial status plus Shenzhen. The data exclude the Special Administrative Zones of Hong Kong and Macau. Mainland China further excludes Taiwan, but we subsequently examine Taiwanese lottery sales for external validity.
} 
Table 1 Summary statistics

\begin{tabular}{|c|c|c|c|c|c|}
\hline Variable & $\mathrm{N}$ & Mean & Std.dev. & $\mathrm{p} 1$ & p99 \\
\hline \multicolumn{6}{|l|}{ An observation is a province by day } \\
\hline Daily 3D lottery sales (CNY million) & 56,320 & 1.43 & 0.98 & 0.04 & 4.41 \\
\hline Public holiday $($ yes $=1$ ) & 56,320 & 0.06 & 0.24 & 0.00 & 1.00 \\
\hline \multicolumn{6}{|l|}{$P_{i t}$, particle (haze) pollution at the surface: } \\
\hline PM2.5, daytime mean 6 am to $8 \mathrm{pm}\left(\mu \mathrm{g} / \mathrm{m}^{3}\right)$ & 56,320 & 51.84 & 41.19 & 8.98 & 213.15 \\
\hline PM2.5, 24-hour mean $\left(\mu \mathrm{g} / \mathrm{m}^{3}\right)$ & 56,320 & 53.05 & 41.06 & 9.52 & 213.81 \\
\hline Difference morning vs. afternoon PM2.5 $\left(\mu \mathrm{g} / \mathrm{m}^{3}\right)$ & 56,071 & 6.16 & 22.47 & -51.18 & 77.00 \\
\hline \multicolumn{6}{|c|}{$W_{i t}$, weather at the surface, mean 8 am $\& 8$ pm: } \\
\hline Temperature $\left({ }^{\circ} \mathrm{C}\right)$ & 56,270 & 14.40 & 10.80 & -14.90 & 31.30 \\
\hline Dew point depression $\left({ }^{\circ} \mathrm{C}\right)$ & 56,270 & 6.91 & 5.50 & 0.35 & 24.50 \\
\hline \multicolumn{6}{|l|}{$A_{i t}$, atmospheric regime, mean 8 am $\& 8$ pm: } \\
\hline \multicolumn{6}{|c|}{ Thermal gradients as altitude increases $\left({ }^{\circ} \mathrm{C}\right.$ differences at standard atmospheric pressure levels) } \\
\hline ...from surface to $1000 \mathrm{mb}$ & 56,270 & 0.11 & 0.87 & -1.60 & 4.00 \\
\hline ...from 1000 to $925 \mathrm{mb}$ & 56,286 & -1.79 & 2.07 & -5.70 & 3.25 \\
\hline ...from 925 to $850 \mathrm{mb}$ & 56,286 & -2.63 & 2.30 & -6.30 & 3.90 \\
\hline ...from 850 to $700 \mathrm{mb}$ & 56,287 & -7.29 & 3.61 & -14.05 & 2.60 \\
\hline ...from 700 to $500 \mathrm{mb}$ & 56,284 & -14.78 & 3.01 & -21.60 & -5.90 \\
\hline Wind speed at the surface $(\mathrm{m} / \mathrm{s})$ & 56,270 & 2.20 & 1.39 & 0.00 & 6.50 \\
\hline \multicolumn{6}{|c|}{ Wind direction at the surface (all hours from a given direction=1) } \\
\hline ...from North & 56,287 & 0.36 & 0.35 & 0.00 & 1.00 \\
\hline ...from East & 56,287 & 0.27 & 0.31 & 0.00 & 1.00 \\
\hline ...from South & 56,287 & 0.20 & 0.29 & 0.00 & 1.00 \\
\hline ...from West & 56,287 & 0.16 & 0.26 & 0.00 & 1.00 \\
\hline \multicolumn{6}{|l|}{ An observation is a day (aggregate data only) } \\
\hline Daily aggregated 3D lottery sales (CNY million) & 1,760 & 45.79 & 4.74 & 36.73 & 58.07 \\
\hline Daily PL3 lottery sales (CNY million) & 1,760 & 15.17 & 1.70 & 12.03 & 19.71 \\
\hline Daily PL5 lottery sales (CNY million) & 1,760 & 9.01 & 0.74 & 7.69 & 10.94 \\
\hline Double Color Ball lottery sales (CNY million) & 753 & 347.07 & 35.40 & 278.53 & 436.73 \\
\hline Lotto 7 lottery sales (CNY million) & 755 & 15.60 & 3.11 & 10.84 & 23.21 \\
\hline Big Lotto lottery sales (CNY million) & 755 & 167.17 & 38.87 & 88.30 & 234.06 \\
\hline Seven Stars lottery sales (CNY million) & 755 & 8.35 & 1.62 & 5.67 & 12.72 \\
\hline Aggregated PM2.5, mean 6 am to $8 \mathrm{pm}\left(\mu \mathrm{g} / \mathrm{m}^{3}\right)$ & 1,760 & 0.54 & 0.25 & 0.22 & 1.42 \\
\hline
\end{tabular}

number lotteries are available only as aggregated data for the entire country without geographic resolution. With about 21 million bets placed daily, 3D sales in 2017 of CNY 16 billion were double that of the other two daily fixed-prize number lotteries, PL3 and PL5, combined. With the availability of daily ambient particle levels by province starting in 2013, we examine daily 3D sales data over the five years 2013 to 2017. 
Table 1 (continued)

\begin{tabular}{llllll}
\hline Variable & $\mathrm{N}$ & Mean & Std.dev. & $\mathrm{p} 1$ & $\mathrm{p} 99$ \\
\hline Aggregated temperature $\left({ }^{\circ} \mathrm{C}\right)$ & 1,760 & 14.18 & 9.03 & -2.69 & 27.31 \\
Aggregated dew point depression $\left({ }^{\circ} \mathrm{C}\right)$ & 1,760 & 6.69 & 2.15 & 2.81 & 12.52 \\
\hline
\end{tabular}

Notes: An observation is a province by day in the top panel, and a day in the bottom panel. 3D lottery sales in the bottom panel are the sum across provinces' 3D sales (the only product with geographically resolved data). Draws for the fixed-prize number lotteries (3D, PL3, and PL5) occur seven days each week. Draws for the variable-prize number lotteries occur on three specific and distributed days each week, e.g., Double Color Balls is drawn on Tuesdays, Thursdays, and Sundays. In the bottom panel, nationally aggregated environmental variables are weighted averages of their provincial-level counterparts, where weights are each province's share of China's aggregate 3D lottery sales over 2013-2017. The sample period is January 18, 2013 to December 19, 2017. The morning-afternoon PM2.5 difference is the 6 am to $12 \mathrm{pm}$ mean minus the $1 \mathrm{pm}$ to $8 \mathrm{pm}$ mean. Sources: http://kaijiang.zhcw.com/zhcw/inc/3d/3d_gsxlzj.jsp, www. 17500 . $\mathrm{cn} /$, http://datachart.500.com/, MEE, NOAA

In the 3D lottery, a player pays CNY 2 and picks three integers (0-9) and one of three possible formats: (i) exact order, (ii) two numbers repeated, and (iii) no repeated numbers. The winning odds is $1 / 1000$ in format (i). For format (ii), the winning odds is $3 / 1000$ since there are three equivalent combinations of any three winning numbers, e.g., 122, 212 or 221. Similarly, the winning odds for format (iii) is 6/1000 since there are six equivalent combinations of three winning numbers, e.g., 149, 194, 419, 491, 914 or 941. The corresponding winning amounts are CNY 1,040, CNY 346, and CNY 173 with expected payoffs of CNY 1.04 for format (i) and CNY 1.038 for formats (ii) and (iii). Online distribution remains restricted, and there were no officially sanctioned online platforms by 2018 (Betting Guide, 2018; xinhuanet.com, 2018b). The day's sales, winning numbers, and number of winners by bet format are broadcast live, at 9 pm, on channel one of the Chinese Education TV Network (CETV-1) (cwl.gov.cn, 2017; AGTech, 2018).

Starting on January 18, 2013, PM2.5 concentrations at all surface-level air monitoring sites-about 1,500 across the country-became available, by hour, through the Chinese Ministry of Ecology and Environment (MEE). For each day and hour, we average across sites within a province to obtain a province-level mean. ${ }^{9}$ For each day, we then average these province-level means over daytime/daylight hours, from 6 am to 8 pm inclusive.

Figure 2 shows wide PM2.5 variability within province over the 1,760 days in the study period, as well as across the 32 provinces. The 10 th percentile in the combined lottery-environment sample over days and provinces is $17 \mu \mathrm{g} / \mathrm{m}^{3}$, already in the range of human visibility (Watson, 2002). Most province-day observations amply exceed the US National Ambient Air Quality Standards, marked by the vertical lines (NAAQS annual at $12 \mu \mathrm{g} / \mathrm{m}^{3}, 24$-hour at $35 \mu \mathrm{g} / \mathrm{m}^{3}$ ). The 90 th percentile at $99 \mu \mathrm{g} / \mathrm{m}^{3}$ is severe. At such a level it is conceivable that individuals reduce their time outdoors including, where not too costly, staying more at home (He et al., 2017). Such

\footnotetext{
${ }^{9}$ This simple averaging procedure places more weight in more populated locations, such as cities, which tend to host more air monitoring sites, besides more potential gamblers.
} 


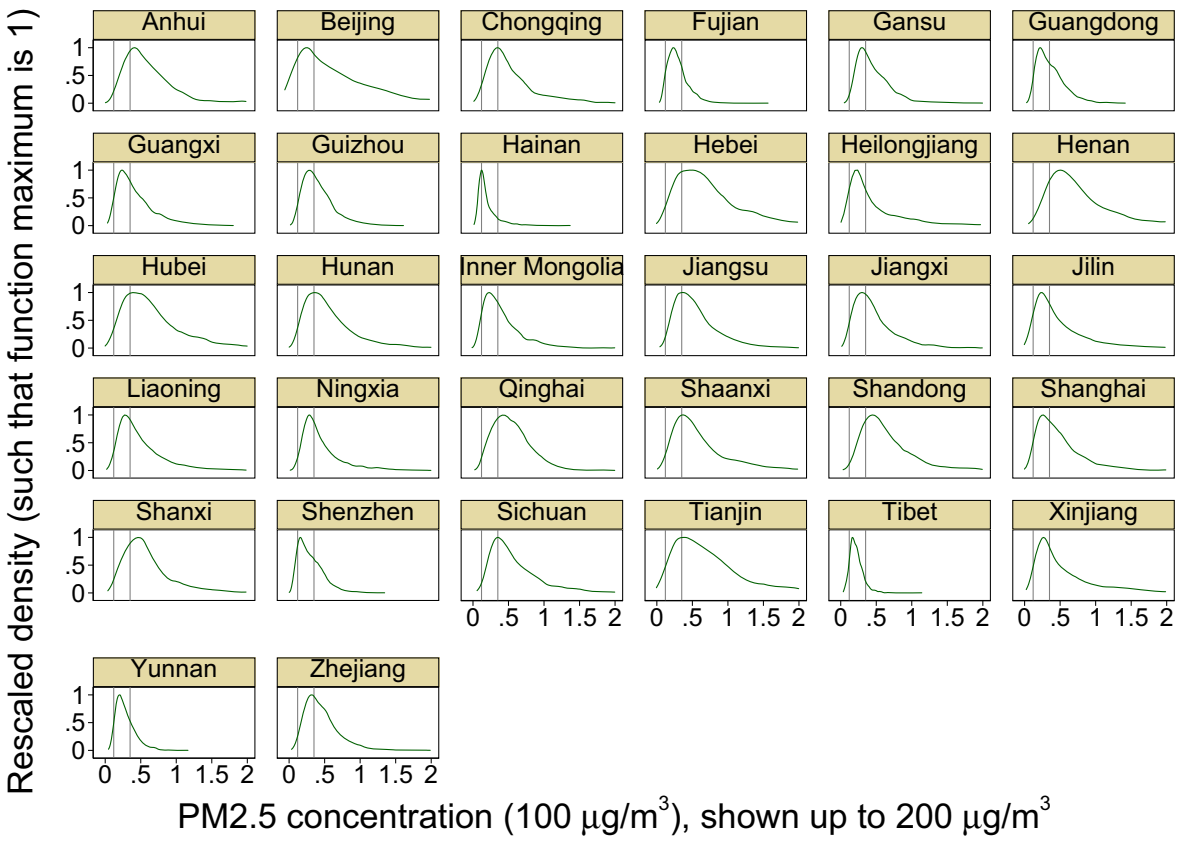

Fig. 2 Distribution of daily mean PM2.5 mass concentrations $\left(\times 10^{2} \mu \mathrm{g} / \mathrm{m}^{3}\right)$ over days (within panel) and across provinces (across panels). We compute daily mean PM2.5 during daytime hours from 6 am to 8 pm, based on hourly PM2.5 averaged across monitoring sites within each province. The sample period is January 2013 to December 2017. For better visualization, we show density up to $200 \mu \mathrm{g} / \mathrm{m}^{3}$ and rescale the density function such that the maximum is 1 (otherwise plots for provinces with high PM2.5 such as Hebei are too flat). The annual and 24-hour US National Ambient Air Quality Standards of 12 and 35 $\mu \mathrm{g} / \mathrm{m}^{3}$ are marked by the vertical lines. Source: MEE

potential avoidance behavior, as we subsequently discuss, would render our estimates conservative.

Besides PM2.5 and seasonal factors, our empirical models allow ambient temperature and humidity to directly affect lottery demand. For example, people may behave differently on a hot and humid summer day. From the US National Oceanic and Atmospheric Administration (NOAA), we obtain surface temperature and dew point depression, recorded every 12 hours, for 93 observatories across China. ${ }^{10}$

In addition, NOAA data for these locations and times include wind speed and direction at surface as well as atmospheric thermal gradients (Table 1). These gradients, which fluctuate exogenously, indicate how temperature varies with altitude and whether there is a layer of warmer air overhead that traps pollutants close to the surface where they are emitted. We use atmospheric thermal gradients to instrument for PM2.5, to the extent that high-frequency unobservable shocks to economic activity are present and significantly influence PM2.5 (Seibert et al., 2000; Tang et al., 2016).

\footnotetext{
${ }^{10}$ Each province is matched to the observatory that is nearest to a province's capital city, with distance ranging from $0 \mathrm{~km}$ (Heilongjiang) to $136 \mathrm{~km}$ (Anhui). The median and 75th percentile observatory-tocapital distance across provinces are $12 \mathrm{~km}$ and $37 \mathrm{~km}$.
} 


\subsection{Adversity-hope hypothesis in the raw data}

With lottery proxying for the demand for hope, the adversity-hope hypothesis is corroborated by Fig. 1 showing a positive relationship between 3D lottery sales against PM2.5 by province-day observation in the absence of any regression controls. To help visualize the data, we subtract province-level means from each variable and show locally weighted polynomial fits. Lottery sales are high in province-days with high and visible environmental degradation. The relationship seen in the raw data is further confirmed by the rigorous regression evidence provided next. The hypothesis is that, via a hope channel, smog and haze shift households' preferences over the timing of uncertainty resolution, thus raising lottery sales.

\subsection{Empirical models of lottery demand}

We estimate variations of the empirical model of lottery demand:

$$
q_{i t}=f\left(P_{i t}, \alpha\right)+W_{i t} \beta_{i}+\gamma_{i t}+\epsilon_{i t}
$$

where the natural logarithm of 3D lottery sales in province $i$ and day $t, q_{i t}$, is regressed on a parametric (e.g., quadratic) function of the key variable of interest $P_{i t}$, province-day specific PM2.5 exposure, and controls. As in other developing countries, PM2.5 dominates China's local air quality indices, with particle levels in outdoor air well in the visible range. The interpretation is that of PM2.5 as a general indicator (Dominici et al., 2010) of the severity of haze, including even smaller particles (ultrafine PM 0.01 to 0.1 ) that are not routinely monitored in China or elsewhere (He et al., 2019). ${ }^{11}$

Province-day specific weather controls $W_{i t}$ include two complete sets of bins, each bin $5^{\circ} \mathrm{C}$ wide, for ambient temperature and dew point depression. ${ }^{12}$ We average variables across a day's two readings, at 8 am and $8 \mathrm{pm}$ local time, prior to taking $5^{\circ} \mathrm{C}$ bins. We interact each set of bins with a complete set of province fixed effects (FE), flexibly allowing for the impact of weather on lottery sales to vary by province.

Time controls $\gamma_{i t}$ include complete sets of month(-of-year) FE, year FE, day-ofweek FE, and a dummy variable for public holidays, to allow for systematic demand shifts over the years in the sample, within year, within week, and with the holiday calendar. We interact each set of time controls (month, year, day-of-week, public holiday) with province FE. This flexibly allows the effects of season on lottery sales

\footnotetext{
${ }^{11}$ That the US State Department monitors PM2.5 in several Chinese cities (and elsewhere in the developing world) underscores the relative threat particles pose. To our knowledge, the US State Department does not monitor air pollutants other than PM2.5.

${ }^{12}$ At a given temperature, relative humidity decreases in the dew point depression. Figs. A.1 to A.3 describe how de-seasoned daily ambient temperature, dew point depression, and PM2.5 co-vary, by province.
} 
to vary by province. We note that 3D sales and PM2.5 co-vary over the seasons, both variables increasing in the more adverse winter months of December-January relative to June-August. Since many factors can explain seasonal correlation, it is absorbed by the $\gamma_{i t}$. A model variant replaces month-by-province FE and year-by-province FE with even tighter month-by-year-by-province FE, i.e., month-of-sample interacted with province.

Winning prizes for the 3D lottery were raised in August 2014, namely from CNY 1,000 to CNY 1,040 (for the exact-order format), from CNY 320 to CNY 346 (two numbers repeated format), and from CNY 160 to CNY 173 (no repeated numbers format). To allow for a change in winning prizes to shift demand, akin to a price change, we include a post August 2014 dummy interacted with province FE in the vector of time controls; this allows for cross-sectional variation in prize sensitivity. Beyond these increases in winning prizes, we note that the price per $3 \mathrm{D}$ bet has not changed from CNY 2 and that the supply of 3D bets is elastic. We thus interpret $\epsilon_{i t}$ as an idiosyncratic demand shock.

By way of sensitivity analysis, we specify a cubic function of PM2.5 instead of a quadratic. Another variant of demand model (5) includes PM2.5 on each of the three preceding calendar days in addition to PM2.5 on the concurrent day of 3D sales. We also interact PM2.5 with dummies for China's six different regions, allowing for geographic variation in the estimated impact of pollution on lottery demand.

Allowing for endogenous PM2.5. We estimate models both by ordinary least squares (OLS) and by two-stage least squares (2SLS). The OLS estimator assumes that PM2.5 exposure is measured without error and that omitted variables that correlate with lottery demand and PM2.5 are absent. This assumption may fail in the presence of components of economic activity that co-vary with emissions and that are not already accounted for by controls $\gamma_{i t}$ that capture systematic province-specific seasonal and day-of-week influences and time trends.

An alternative 2SLS estimator assumes that whether the atmosphere is stagnant or well ventilated has no bearing on other possible drivers of lottery demand, such as economic activity. These atmospheric regime shifts, which we observe through recorded thermal gradients, are excluded from equation (5), only affecting lottery demand through PM2.5 (Zhang et al., 2015; Tang et al., 2016; Liu \& Salvo, 2018; He et al., 2019). Province-day specific atmospheric regime conditions, denoted by $A_{i t}$, are a key determinant of local PM2.5 (Figs. A.4 and A.5) and are unlikely to correlate with unobserved lottery demand shocks, $\epsilon_{i t}$ (exogeneity). ${ }^{13}$

The 2SLS identifying assumption would be violated were a special kind of pollution control policy in place. Consider a hypothetical scenario in which emissions

\footnotetext{
${ }^{13}$ Using $A_{i t}$-induced PM2.5 circumvents the unobservable presence of lottery demand influences that may co-vary with PM2.5 and confound our estimate of the causal effect of haze on lottery demand. Intuitively, while OLS relies on all PM2.5 variation after accounting for weather, season, and trends at the provincial level, 2SLS relies only on regime-induced PM2.5 shifts that plausibly do not co-vary with potentially confounding economic activity.
} 
permits issued by a strong and well-informed regulator responded to day-to-day atmospheric regime shifts. In this hypothetical scenario, 2SLS estimates may be downward biased (conservative). For instance, atmospheric stagnation would lower industrial activity as regulators attempted to mitigate the high PM2.5 levels; canceled work shifts would reduce the purchase of lottery tickets through an income channel or a decline in commuter traffic (less workers passing by street-based lottery outlets on their way to work). We do not believe that such a scenario befits China's environmental regulations and, in any case, such a scenario would render our 2SLS estimates conservative.

To use a household analogy for air pollutant dispersion and removal, shifting from a stagnant to a well-ventilated atmosphere is akin to flushing the toilet. Figs. A.4 and A.5 illustrate the strong correlation between PM2.5 and key elements of $A_{i t}$ : (i) thermal gradients and (ii) wind. PM2.5 tends to be high: (i) when there is a positive (less negative) atmospheric temperature gradient in altitude, as the thermal inversion traps surface emissions, ${ }^{14}$ and (ii) when horizontal dissipation is poor, characterized by low wind speeds.

We thus use atmospheric removal conditions $A_{i t}$ to form an instrument for measured pollution $P_{i t}$, estimating the following auxiliary equation by OLS flexibly by province $i$ :

$$
P_{i t}=A_{i t} \phi_{i}+\delta_{i t}+v_{i t},
$$

Included in $A_{i t}$ are linear and quadratic terms for thermal gradients in the atmosphere's five layers closest to the surface and wind speed, as well as wind direction. ${ }^{15}$ To account for the build-up of particles during multi-day inversion episodes, we include same-day and prior-day conditions, and interact a dummy for light wind (up to $1 \mathrm{~m} / \mathrm{s}$ ) with each thermal gradient. $\delta_{i t}$ are time fixed effects (month-by-year, day-of-week, public holiday), and $v_{i t}$ is a disturbance.

We fit $\hat{P}_{i t}$ using the auxiliary atmospheric regime-pollution model (6) and employ these fitted values to instrument for measured $P_{i t}$ in the lottery demand equation (5). To obtain 2SLS estimates, we still generate first-stage predictions of $P$ from the excluded instrument $\hat{P}_{i t}$ and the non-pollution covariates in the second-stage lottery demand equation. ${ }^{16}$

To be clear, $A_{i t}$ does not include surface temperature or humidity, which we allow to directly affect lottery demand. Our results are robust to dropping wind speed from $A_{i t}$ and instead modeling this variable as a lottery demand shifter $W_{i t}$ in (5). In our setting, winds are mild and unlikely to affect lottery demand. Wind speeds average

\footnotetext{
${ }^{14}$ The label inversion reflects the fact that gradients are usually negative, i.e., temperatures drop at higher altitudes. The reported patterns, and the recent PM2.5 records (Ghanem \& Zhang, 2014), bolster our confidence both in the quality of the environmental data and in the identifying strategy.

${ }^{15}$ Table 1 describes these variables. We compute temperature differences between the following pressure points in the lower atmosphere: (1) from surface to $1000 \mathrm{mb}$, (2) 1000 to $925 \mathrm{mb}$, (3) 925 to $850 \mathrm{mb}$, (4) 850 to $700 \mathrm{mb}$, and (5) 700 to $500 \mathrm{mb}$. Table A.5 further lists elements of $A_{i t}$.

${ }^{16}$ Isen et al. (2017a), Liu and Salvo (2018), and He et al. (2019) similarly instrument for pollution using fitted pollution imputed, respectively, from policy and atmospheric interventions. As an alternative to using fitted values from (6), we can use $A_{i t}$ to instrument for pollution (Angrist \& Krueger, 2001)—see Table A.5 for sensitivity analysis. Fig. A.6 reports on instrument strength.
} 


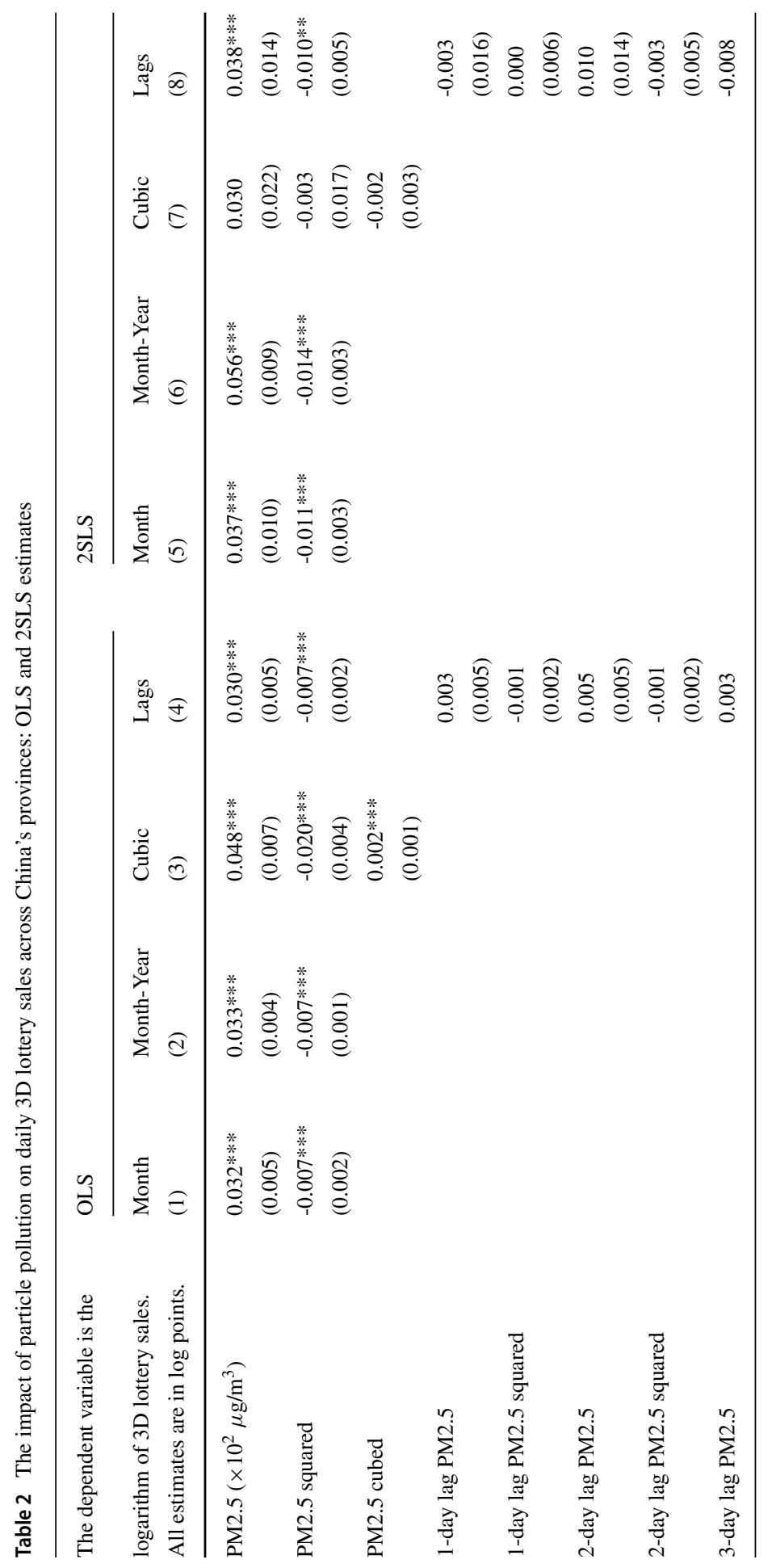




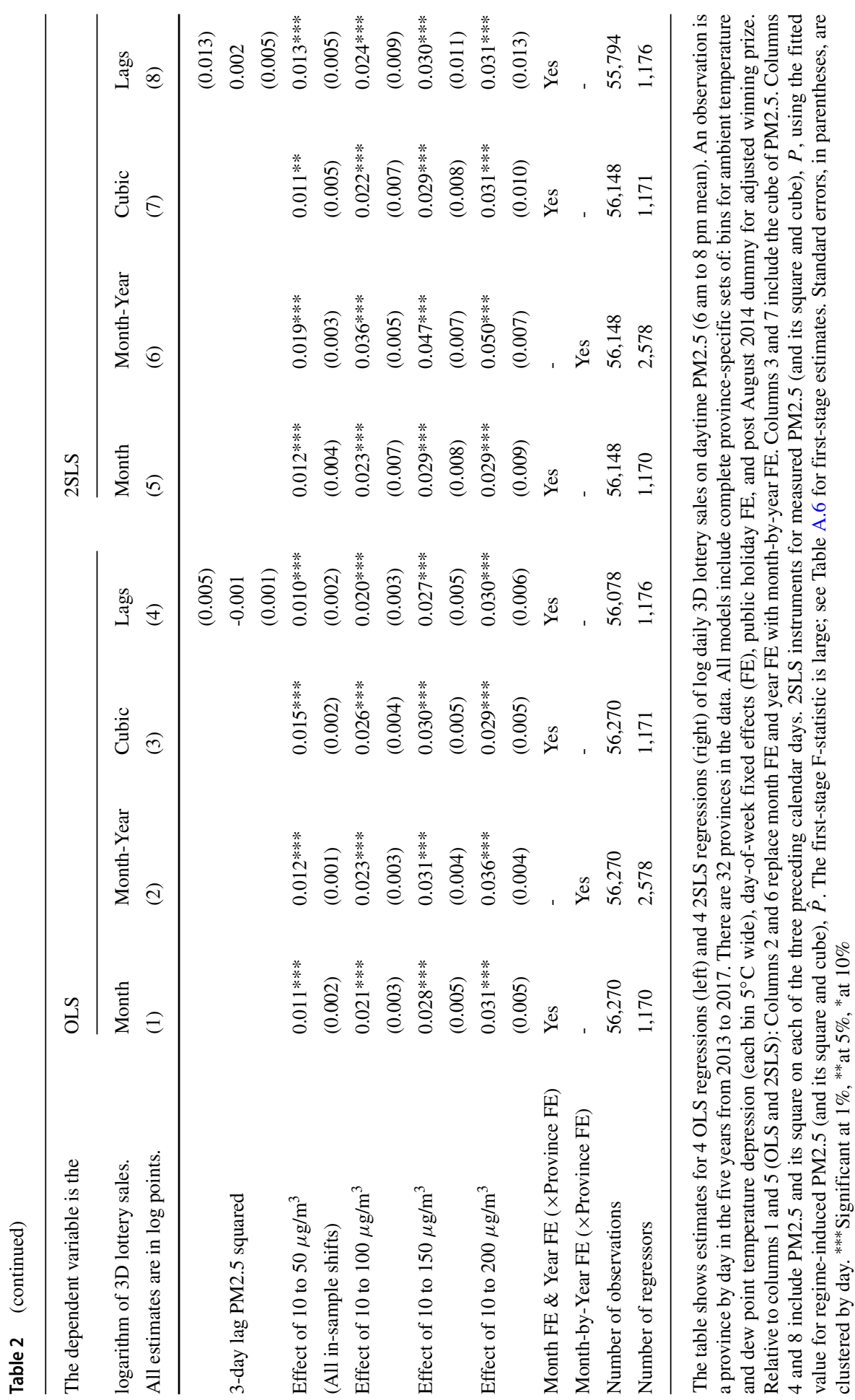


$2.2 \mathrm{~m} / \mathrm{s}$ compared to $4.6 \mathrm{~m} / \mathrm{s}$ and 3-4 m/s in Chicago and Los Angeles (Herrnstadt et al., 2019, 2021; Anderson 2020).

\subsection{Adversity in environment increases lottery demand}

Table 2 reports estimates for alternative models of the causal effect of PM2.5 pollution on daily 3D lottery demand. Impacts estimated with 2SLS, in specifications 5 to 8 , are somewhat larger than with OLS, in specifications 1 to 4 . This is consistent with either some measurement error in pollution exposure or some unobserved dayto-day variation in economic activity and emissions, which the 2SLS models account for. For instance, on unobservable busy days workers/individuals have less time to purchase lotteries and emissions are higher, suggesting downward biased OLS estimates. In specifications 1 (OLS) and 5 (2SLS), with a quadratic in daytime PM2.5, a shift from 10 to $50 \mu \mathrm{g} / \mathrm{m}^{3}$ increases a day's 3D sales by 1.1-1.3 log points, with day-clustered standard errors of 0.2-0.3 log points (the dependent variable is the log of sales). 2SLS estimates are generally less precise. The coefficient on the quadratic term is negative such that pollution's marginal effect falls as PM2.5 rises from 10 $\mu \mathrm{g} / \mathrm{m}^{3}$ (the first percentile of PM2.5 over days and provinces). Figure 3 visualizes the impact of a large_-but still in sample-PM2.5 shift from 10 to $200 \mu \mathrm{g} / \mathrm{m}^{3}$, converted

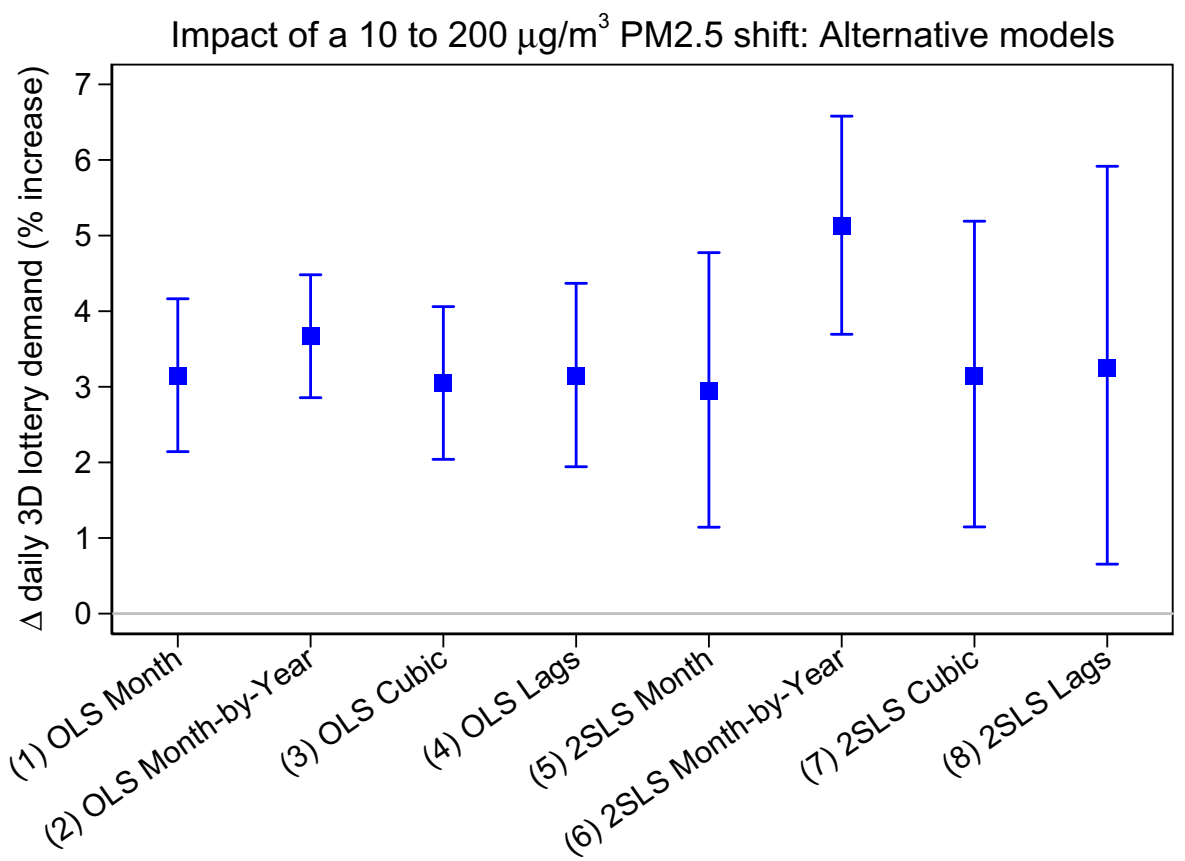

Fig. 3 Percent increase in daily 3D lottery demand due to a 10 to $200 \mu \mathrm{g} / \mathrm{m}^{3}$ in-sample shift in daytime PM2.5 levels ( 6 am to $8 \mathrm{pm}$ mean). The figure plots the $95 \%$ confidence interval for the PM2.5 impact based on each of the 8 OLS and 2SLS regression models reported in Table 2, implemented on the 3D province-day sample 
to a $95 \%$ confidence interval (CI) of percentage increase: Lottery demand increases by about 3.0 percent in specifications 1 and 5 .

In specifications 2 and 6, estimates grow on replacing month-by-province and year-by-province intercepts with more flexible month-by-year-by-province intercepts. The effect of PM2.5 on lottery demand is now estimated from co-variation within month-of-sample and province. These detailed controls absorb a few isolated spikes (e.g., Beijing in October 2014) and breaks (e.g., Jianxi from March 2015 on) that we observe in the sales data. In specifications 3 and 7, estimated impacts are similar when we add a cubic term in PM2.5, suggesting that the quadratic form is not restrictive. Estimates on same-day PM2.5 are similar, in specifications 4 and 8 , when we include linear and quadratic terms for PM2.5 in each of the three days preceding the specific daily draw. Across all models in Fig. 3 (Table 2), the impact of a 10 to $200 \mu \mathrm{g} / \mathrm{m}^{3}$ PM2.5 shift on daily 3D lottery demand ranges from +2.9 to +5.1 percent, and is significant at the $1 \%$ level throughout.

In Table A.1, we repeat the quadratic PM2.5 specification on separate sub-samples by region of China (north, northeast, northwest, east, southwest, and southcentral). OLS estimates are positive for all regional sub-samples, and statistically significant for six of the seven regions. 3D sales impacts range from +1.6 to +7.4 percent for a 10 to $200 \mu \mathrm{g} / \mathrm{m}^{3}$ PM2.5 shift. 2SLS estimates are more dispersed, ranging from 0.0 to +13.3 percent, and less precise. (We discuss the case of independently managed Taiwan below.)

Table 3 restricts the sample to the two municipalities with province status in the 3D lottery data, Beijing and Shanghai, where the US State Department monitors PM2.5 since 2008 and 2011, respectively. We use US State Department rather than MEE PM2.5 records at these granular geographic areas (cities, not provinces), add controls for daytime precipitation (obtained from NASA), and temporally extend the sample over one decade. Similar estimates based on alternative US State Department pollution records for two major cities reassure us of our findings. ${ }^{17}$

Table 4 shows evidence that morning PM2.5 impacts lottery sales more than afternoon PM2.5. Fixing a change in the daytime mean PM2.5 (6 am to $8 \mathrm{pm}$ ), say from 10 to $200 \mu \mathrm{g} / \mathrm{m}^{3}$, the impact on lottery sales is more pronounced when the morning is polluted (and the afternoon has cleared) than when the onset of haze happens in the afternoon (and the morning was clear). We interpret this pattern as being consistent with an individual spending the day savoring the prospect of winning, ahead of the resolution of uncertainty.

\subsubsection{Robustness}

The Appendix provides further sub-sample analysis and robustness tests. Table A.2 shows OLS and 2SLS estimates for the quadratic PM2.5 specification implemented

\footnotetext{
${ }^{17}$ These regressions further indicate that 3D lottery sales fall by about 4 percent in both Beijing and Shanghai when daytime rainfall exceeds $4 \mathrm{~mm}$. Controlling for rain slightly reduces the impact of PM2.5 on 3D sales. This is consistent with the notion that heavy rain, while uncommon, may wash out particles and, at the same time, lead to less gamblers visiting lottery outlets (due to avoidance of rain).
} 
Table 3 PM2.5 recorded by the US State Department for two municipalities over a decade

\begin{tabular}{|c|c|c|c|c|}
\hline \multirow{2}{*}{$\begin{array}{l}\text { The dependent variable is the } \\
\text { logarithm of 3D lottery sales. } \\
\text { All estimates are in log points. }\end{array}$} & \multicolumn{2}{|l|}{ OLS } & \multicolumn{2}{|l|}{ 2SLS } \\
\hline & $\begin{array}{l}\text { Month } \\
\text { (1) }\end{array}$ & $\begin{array}{l}\text { Month-Year } \\
\text { (2) }\end{array}$ & $\begin{array}{l}\text { Month } \\
\text { (3) }\end{array}$ & $\begin{array}{l}\text { Month-Year } \\
\text { (4) }\end{array}$ \\
\hline PM2.5 $\left(\times 10^{2} \mu \mathrm{g} / \mathrm{m}^{3}\right)$ & $\begin{array}{l}0.027 * * * \\
(0.009)\end{array}$ & $\begin{array}{l}0.012 * * \\
(0.005)\end{array}$ & $\begin{array}{l}0.050 * * * \\
(0.015)\end{array}$ & $\begin{array}{l}0.032 * * * \\
(0.010)\end{array}$ \\
\hline PM2.5 squared & $\begin{array}{l}-0.003 \\
(0.002)\end{array}$ & $\begin{array}{l}-0.000 \\
(0.001)\end{array}$ & $\begin{array}{l}-0.010 * * * \\
(0.004)\end{array}$ & $\begin{array}{l}-0.008 * * * \\
(0.003)\end{array}$ \\
\hline Effect of 10 to $50 \mu \mathrm{g} / \mathrm{m}^{3}$ & $\begin{array}{l}0.010^{* * *} \\
(0.003)\end{array}$ & $\begin{array}{l}0.005^{* * *} \\
(0.002)\end{array}$ & $\begin{array}{l}0.018^{* * * *} \\
(0.005)\end{array}$ & $\begin{array}{l}0.011 * * * \\
(0.003)\end{array}$ \\
\hline Effect of 10 to $100 \mu \mathrm{g} / \mathrm{m}^{3}$ & $\begin{array}{l}0.021 * * * \\
(0.006)\end{array}$ & $\begin{array}{l}0.011 * * * \\
(0.004)\end{array}$ & $\begin{array}{l}0.035^{* * * *} \\
(0.010)\end{array}$ & $\begin{array}{l}0.021 * * * \\
(0.007)\end{array}$ \\
\hline Effect of 10 to $150 \mu \mathrm{g} / \mathrm{m}^{3}$ & $\begin{array}{l}0.031 * * * \\
(0.008)\end{array}$ & $\begin{array}{l}0.017 * * * \\
(0.005)\end{array}$ & $\begin{array}{l}0.047 * * * \\
(0.013)\end{array}$ & $\begin{array}{l}0.027 * * * \\
(0.009)\end{array}$ \\
\hline Effect of 10 to $200 \mu \mathrm{g} / \mathrm{m}^{3}$ & $\begin{array}{l}0.038^{* * *} \\
(0.010)\end{array}$ & $\begin{array}{l}0.022 * * * \\
(0.006)\end{array}$ & $\begin{array}{l}0.055^{* * * *} \\
(0.015)\end{array}$ & $\begin{array}{l}0.030 * * * \\
(0.010)\end{array}$ \\
\hline Month FE \& Year FE ( $\times$ City FE) & Yes & - & Yes & - \\
\hline Month-by-Year FE ( × City FE) & - & Yes & - & Yes \\
\hline Number of observations & 5,088 & 5,088 & 5,084 & 5,084 \\
\hline Number of regressors & 88 & 225 & 88 & 225 \\
\hline R-squared & 0.887 & 0.966 & & \\
\hline First-stage F-statistic & & & 35.598 & 38.452 \\
\hline
\end{tabular}

The table shows estimates for 2 OLS regressions (left) and 2 2SLS regressions (right) of log daily 3D lottery sales on daytime PM2.5. The estimation sample is restricted to Beijing and Shanghai, the two municipalities with province status in the 3D lottery data where the US State Department monitors PM2.5, starting as far back as April 2008 in Beijing and January 2011 in Shanghai, until June 2017. Here we use PM2.5 levels according to the US State Department, not MEE data as in Table 2 (available only since 2013). An observation is a municipality by day. On top of the province-specific weather and time controls included in the specifications of Table 2, we control for city-level precipitation, downloaded from NASA, with separate bins for no rainfall, up to $1 \mathrm{~mm}, 1$ to $4 \mathrm{~mm}$, and over $4 \mathrm{~mm}$ (sum of rainfall from 6 am to 8 pm). Columns 1 and 3 (OLS and 2SLS) specify month-by-city FE and year-by-city FE. Columns 2 and 4 specify month-by-year-by-city FE. 2SLS instruments for measured PM2.5 (and its square), $P$, using the fitted value for regime-induced PM2.5 (and its square), $\hat{P}$. Standard errors, in parentheses, are clustered by day. ${ }^{* * *}$ Significant at $1 \%,{ }^{* *}$ at $5 \%,{ }^{*}$ at $10 \%$

separately on (i) the 16 provinces with higher PM2.5 in the sample; (ii) the 16 less polluted provinces; (iii) the colder and often more polluted season from October to March; and (iv) the warmer April to September season. PM2.5's estimated impact on daily 3D demand is similar and significant whether we stratify the sample by provinces' typical air quality or by season.

Table A.3 reports on several robustness tests, with similar positive and significant effects estimated throughout. Estimates hardly change when we replace the $5^{\circ} \mathrm{C}$ wide ambient temperature bins by a quadratic in temperature, continuing to interact temperature covariates with province intercepts for flexibility. Effects shrink slightly 
Table 4 The impact of morning vs. afternoon pollution on daily 3D lottery sales

\begin{tabular}{|c|c|c|}
\hline \multirow{2}{*}{$\begin{array}{l}\text { The dependent variable is the } \\
\text { logarithm of 3D lottery sales. } \\
\text { All estimates are in log points. }\end{array}$} & \multicolumn{2}{|c|}{ Morning PM2.5 minus afternoon PM2.5 } \\
\hline & $\begin{array}{l}\text { 10th percentile } \\
\text { at }-11 \mu \mathrm{g} / \mathrm{m}^{3}\end{array}$ & $\begin{array}{l}\text { 90th percentile } \\
\text { at }+27 \mu \mathrm{g} / \mathrm{m}^{3}\end{array}$ \\
\hline OLS & (1a) & (1b) \\
\hline Effect of 10 to $50 \mu \mathrm{g} / \mathrm{m}^{3}$ (daytime mean) & $\begin{array}{l}0.011 * * * \\
(0.002)\end{array}$ & $\begin{array}{l}0.012 * * * \\
(0.002)\end{array}$ \\
\hline Effect of 10 to $100 \mu \mathrm{g} / \mathrm{m}^{3}$ (daytime mean) & $\begin{array}{l}0.021 * * * \\
(0.004)\end{array}$ & $\begin{array}{l}0.025 * * * \\
(0.004)\end{array}$ \\
\hline Effect of 10 to $150 \mu \mathrm{g} / \mathrm{m}^{3}$ (daytime mean) & $\begin{array}{l}0.027 * * * \\
(0.005)\end{array}$ & $\begin{array}{l}0.033 * * * \\
(0.005)\end{array}$ \\
\hline Effect of 10 to $200 \mu \mathrm{g} / \mathrm{m}^{3}$ (daytime mean) & $\begin{array}{l}0.030 * * * \\
(0.006)\end{array}$ & $\begin{array}{l}0.037 * * * \\
(0.006)\end{array}$ \\
\hline 2SLS & $(2 a)$ & $(2 b)$ \\
\hline Effect of 10 to $50 \mu \mathrm{g} / \mathrm{m}^{3}$ (daytime mean) & $\begin{array}{l}0.008 * * \\
(0.004)\end{array}$ & $\begin{array}{l}0.026 * * * \\
(0.007)\end{array}$ \\
\hline Effect of 10 to $100 \mu \mathrm{g} / \mathrm{m}^{3}$ (daytime mean) & $\begin{array}{l}0.015^{*} \\
(0.008)\end{array}$ & $\begin{array}{l}0.048 * * * \\
(0.013)\end{array}$ \\
\hline Effect of 10 to $150 \mu \mathrm{g} / \mathrm{m}^{3}$ (daytime mean) & $\begin{array}{l}0.016 \\
(0.010)\end{array}$ & $\begin{array}{l}0.059 * * * \\
(0.015)\end{array}$ \\
\hline Effect of 10 to $200 \mu \mathrm{g} / \mathrm{m}^{3}$ (daytime mean) & $\begin{array}{l}0.014 \\
(0.011)\end{array}$ & $\begin{array}{l}0.058 * * * \\
(0.016)\end{array}$ \\
\hline
\end{tabular}

Notes: The table shows estimates for 1 OLS regression (with impacts shown in columns $1 \mathrm{a}$ and $1 \mathrm{~b}$ ) and 1 2SLS regression (in columns $2 \mathrm{a}$ and $2 \mathrm{~b}$ ) of log daily 3D lottery sales on daytime PM2.5. An observation is a province by day (2013 to $2017, N=56,021$ in the OLS regression and $N=54,906$ in the 2SLS regression). Consider the difference in morning PM2.5 (6 am to $12 \mathrm{pm})$ and afternoon PM2.5 (1 pm to $8 \mathrm{pm}$ ), i.e., this is positive (resp., negative) if PM2.5 is higher (resp., lower) in the morning than in the afternoon (Table 1). Models follow specifications 1 and 5 (OLS and 2SLS) of Table 2 except that we include as regressors the morning-afternoon PM2.5 difference and interactions of this morning-afternoon PM2.5 difference with daytime PM2.5 (and its square). We report the effect of daytime PM2.5 shifts (e.g., 10 to $50 \mu \mathrm{g} / \mathrm{m}^{3}$ ) when the morning-afternoon PM2.5 difference is low and negative (equal to the 10th percentile at $-11 \mu \mathrm{g} / \mathrm{m}^{3}$ ), and when the morning-afternoon PM2.5 difference is high and positive (equal to the 90th percentile at $+27 \mu \mathrm{g} / \mathrm{m}^{3}$ ). We fit the morning-afternoon PM2.5 difference using an auxiliary atmospheric regime-pollution model (6) that takes as regressors atmospheric regime conditions $A_{i t}$ (e.g., thermal gradients) separately at 8 am and at $8 \mathrm{pm}$. 2SLS then instruments for the measured morningafternoon PM2.5 difference, daytime PM2.5 (as in Table 2), and interactions using the corresponding levels and interactions of these variables' fitted values, fitted from atmospheric regime shifts. ${ }^{* * *}$ Significant at $1 \%,{ }^{* *}$ at $5 \%,{ }^{*}$ at $10 \%$

when we progressively drop dew point depression and temperature controls, or when we correct for seasonality using week-of-year rather than month-of-year intercepts (always interacted with province). Very granular week controls likely absorb some variation of interest-and Table A.4 follows Isen et al. (2017b) and goes further still, specifying day-of-year rather than month-of-year or week-of-year. 


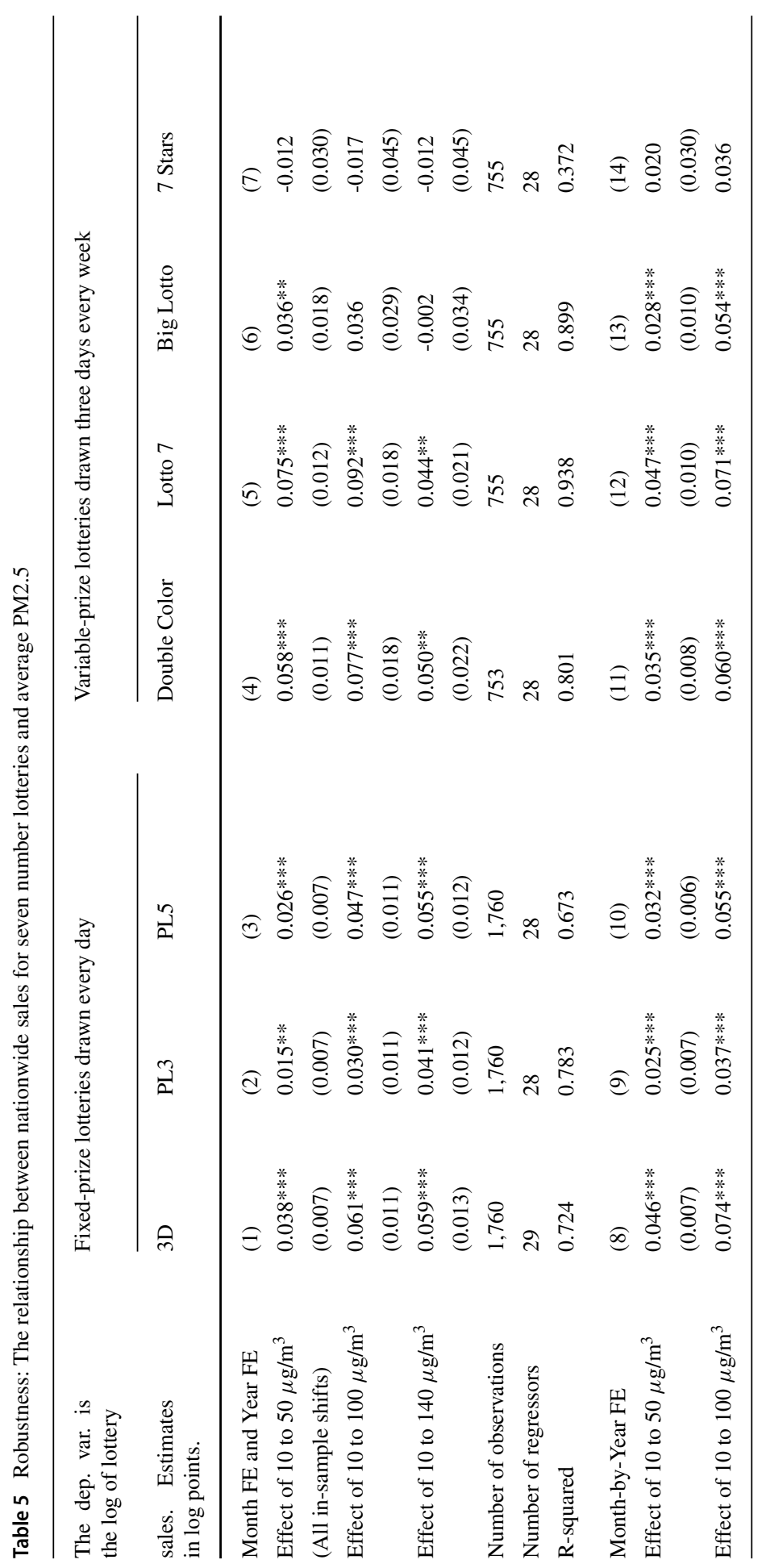




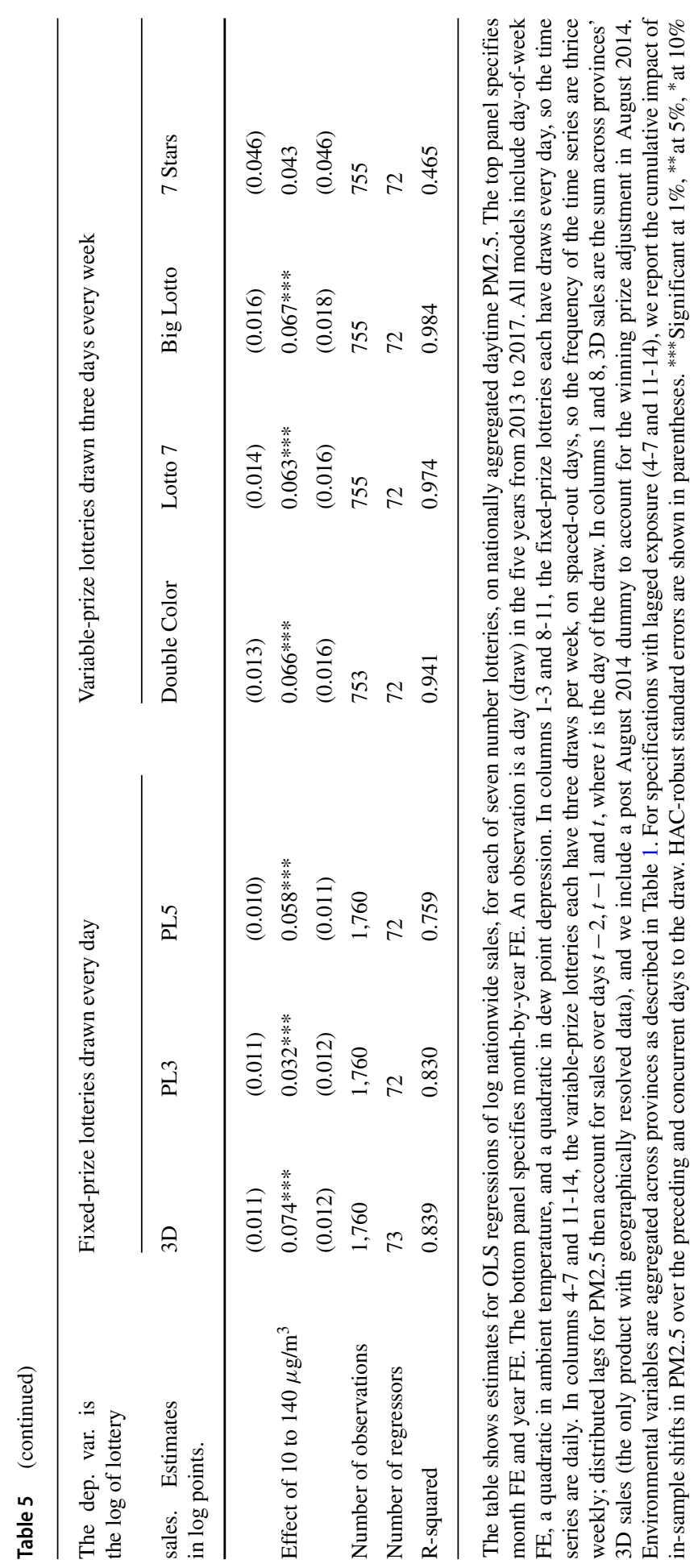


Continuing with Table A.3, similar results obtain when replacing year intercepts with a trend (again province-specific), or when the estimation sample is trimmed at the 1st and 99th percentiles of the province-specific distribution of daily 3D sales or restricted to weekdays outside of public holidays. We also specify daily PM2.5 as the 24-hour mean rather than the 15-hour daytime mean. Table A.7 shows sensitivity analysis to the parametric form of PM2.5, specifying PM2.5 (i) in bins, (ii) as a linear spline function with knots set at 50 and $100 \mu \mathrm{g} / \mathrm{m}^{3}$, and (iii) in logarithmic form, as alternatives to the quadratic and cubic functional forms of Table 2. We find a robust concave lottery demand response to air pollution. Finally, weighting the regression by a province's 2010 Census population yields similar estimates (not shown).

\subsubsection{Demand for other number lotteries}

We find that demand for other number lotteries, with available data aggregated for the entire country, is positively associated with a weighted average for PM2.5 across China. Besides the 3D examined above, we consider the two other fixed-prize lotteries and the four variable-prize lotteries offering highly skewed prospects of winning millions of CNY (in contrast to CNY 1,000 in the 3D). The PL3 lottery has the same rules as the 3D. The PL5 lottery pays CNY 100,000 if a player picks five winning integers (0-9) in the exact order. Like the 3D, each PL3 and PL5 bet costs CNY 2. The rules for variable-prize lotteries are detailed in the Appendix.

Table 5 reports OLS estimates for the log of each product's nationwide salesvarying daily in the case of fixed-prize lotteries, and thrice weekly otherwiseregressed on a quadratic function of average PM2.5 with controls for weather and time. Nationally aggregated environmental variables are weighted averages of their provincial-level counterparts, where the weights are the provincial shares of China's 2013-2017 3D lottery sales (results are similar if we use population shares as weights).

The top panel controls for month and year intercepts whereas the bottom panel specifies month-by-year intercepts to better account for fluctuating sales over the period. For comparability, columns 1 and 8 report on aggregated 3D lottery sales. Figure 4 shows the corresponding 95\% CI. In columns 2 and 3, an in-sample aggregate PM2.5 shift from 10 to $140 \mu \mathrm{g} / \mathrm{m}^{3}$ is associated with statistically significant increases in aggregate PL3 and PL5 lottery sales, of 4.2 and 5.7 percent respectively. With more flexible month-by-year intercepts, columns 9 and 10 show increases of 3.3 and 6.0 percent. Despite the use of a different data source, namely the Sports Lottery, the observed pattern is consistent with that of the 3D from the Welfare Lottery.

Estimated associations for PM2.5 and variable-prize lottery sales are mostly significantly positive. In columns 11 to 14 , a 10 to $140 \mu \mathrm{g} / \mathrm{m}^{3} \mathrm{PM} 2.5 \mathrm{shift}$ is associated with Double Color Balls, Lotto 7, Big Lotto, and 7 Stars sales increases of 6.8, 6.5, 6.9 , and 4.4 percent, all positive and the first three separately statistically significant (7 Stars is the smaller of the four by sales). Since the variable-prize lotteries are drawn only three times per week, on spaced-out days, here we add lagged PM2.5 exposure (and report the cumulative impact) to account for sales on days preceding a draw. Despite the loss of geographic resolution, we are reassured by the results from 


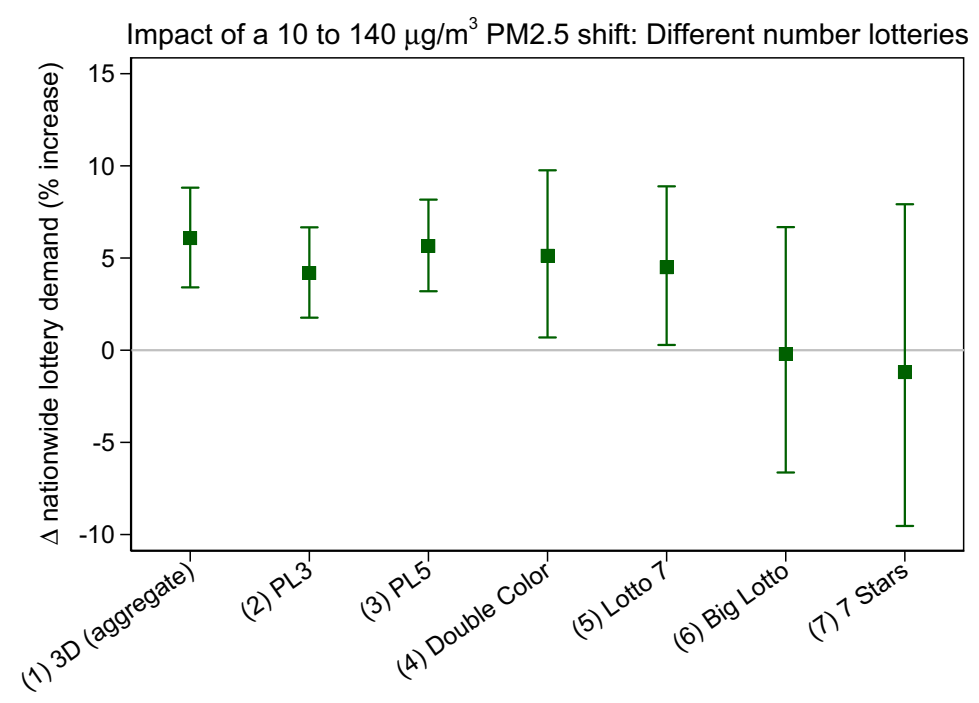

(a) Models with month intercepts and year intercepts

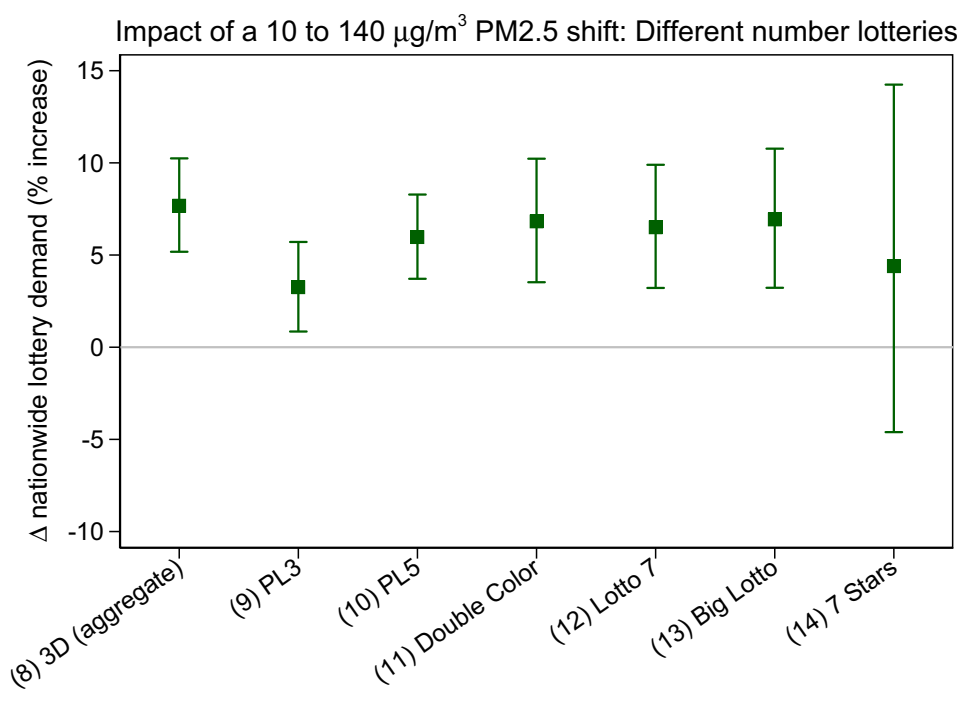

(b) Models with more flexible month-by-year intercepts

Fig. 4 Percent increase in the nationwide sales of seven number lotteries associated with a 10 to 140 $\mu \mathrm{g} / \mathrm{m}^{3}$ in-sample shift in PM2.5, averaged across China. The figure plots the $95 \%$ confidence interval associated with a PM2.5 shift based on the OLS regression models reported in Table 5, implemented on daily time series (3D, PL3, and PL5 fixed-prize lotteries drawn every day) or thrice weekly time series (Double Color Balls, Lotto 7, Big Lotto, and 7 Stars variable-prize lotteries drawn three days every week). Models 1-7 specify month and year intercepts (top panel). Models 8-14 specify month-by-year intercepts (bottom panel) 
the nationwide time series. These are illustrated in the scatterplots of Fig. 5, showing aggregated sales for the different lotteries against aggregated PM2.5.

\subsubsection{External validity: Taiwan}

Authorities in Taiwan sell daily fixed-prize number lotteries that are very similar to (mainland) China's 3D, PL3, and PL5 (Taiwanlottery.com.tw, 2019). Taiwan's threeand four-digit 3D and 4D are similarly popular as their counterparts in China. A time series of daily sales across Taiwan is publicly available for the period 2014 to 2018 . Exposure to particle pollution in Taiwan tends to be lower than in mainland China, yet PM2.5 routinely rises above the US NAAQS and varies in the range of human visibility. Here we look to this independently provided dataset for validity of our main analysis. We find that in Taiwan, too, PM2.5 significantly raises daily lottery demand.

The provider, Taiwan's state-run Welfare Lottery, is not related to China's lottery authorities. Similar to China's 3D, Taiwan's 3D and 4D run daily (except on Sunday), with winning numbers drawn between 8 and $9 \mathrm{pm}$. To place a bet in either the 3D or the 4D, a player pays 25 New Taiwan dollars (NT\$), or about US\$ 0.80, and picks three integers in the $3 \mathrm{D}$, or four integers in the $4 \mathrm{D}$. Top prizes are paid out if a bet matches the winning number in exact order, with winning odds and winning amounts of, respectively, 1/1000 and NT\$12,500 in the 3D, and 1/10,000 and NT\$125,000 in the 4D (and expected payoffs of NT\$12.5 alike). As in China's 3D, betting formats other than the exact-order format can be purchased. We obtained publicly available daily sales spatially aggregated for Taiwan over the five-year period between January 2014 and December 2018. ${ }^{18}$

Hourly PM2.5 concentrations at all surface-level air monitoring sites-76 sites across 22 Taiwanese cities-are available from Taiwan's Environmental Protection Administration. Following our main analysis of lottery demand in China, for each day and hour, we average PM2.5 across sites within a city; for each day, we then average these city-level means over daytime hours, from 6 am to $8 \mathrm{pm}$. Finally, Taiwanaggregated PM2.5 are population-weighted averages of city-level daytime PM2.5. We obtain Taipei's surface and atmospheric meteorological conditions, recorded every 12 hours, from NOAA. Again following our main analysis, NOAA data provides times series of weather controls $W_{t}$, namely ambient temperature and dew point depression, and of atmospheric pollutant removal variables $A_{t}$.

Table 6 reports estimates for OLS and 2SLS models of the causal effect of PM2.5 pollution on daily 3D and 4D lottery demand in Taiwan. Since the 90th and 99th percentiles of daytime PM2.5 in the combined lottery-environment sample for Taiwan are $35 \mu \mathrm{g} / \mathrm{m}^{3}$ and $50 \mu \mathrm{g} / \mathrm{m}^{3}$ (compared with $99 \mu \mathrm{g} / \mathrm{m}^{3}$ and $214 \mu \mathrm{g} / \mathrm{m}^{3}$ in the mainland China sample), we report the impact of a PM2.5 shift from 10 to $50 \mu \mathrm{g} / \mathrm{m}^{3}$. We find that PM2.5 significantly increases 3D and 4D lottery sales. While point estimates

\footnotetext{
${ }^{18}$ For brevity, Table 1 does not describe this additional lottery-environment sample. Sources include http:// www.taiwanlottery.com.tw/Lotto/4D/history.aspx, Taiwan's Ministry of the Interior, and https://taqm.epa. gov.tw/taqm/en/default.aspx.
} 


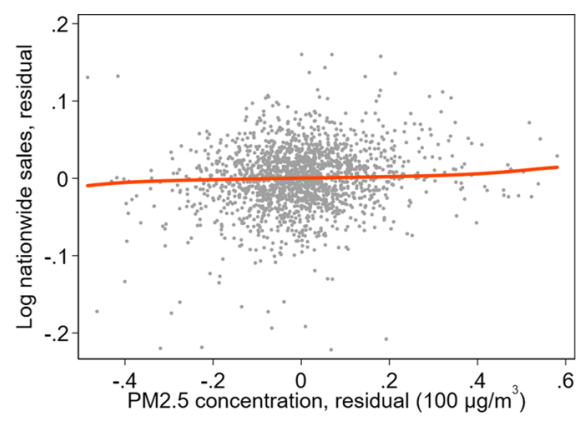

(a) Daily aggregated 3D lottery sales

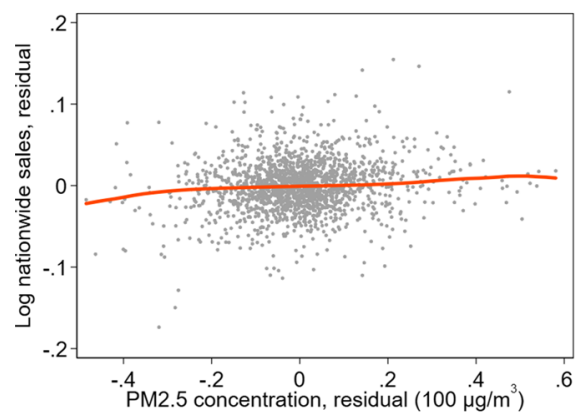

(c) Daily PL5 lottery sales

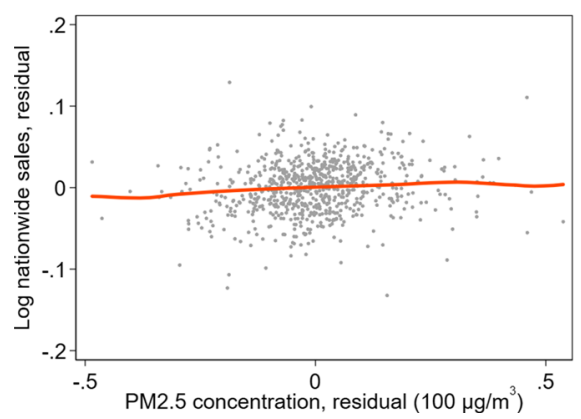

(e) Lotto 7 lottery sales

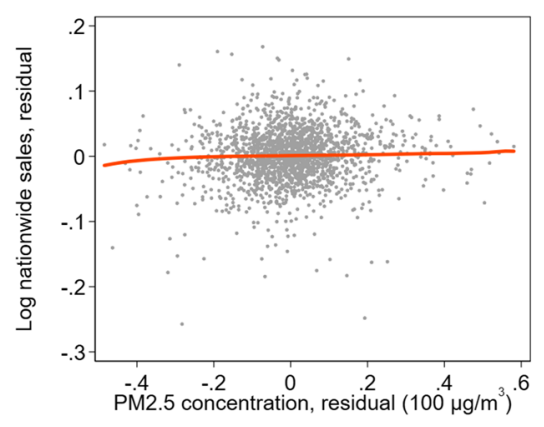

(b) Daily PL3 lottery sales

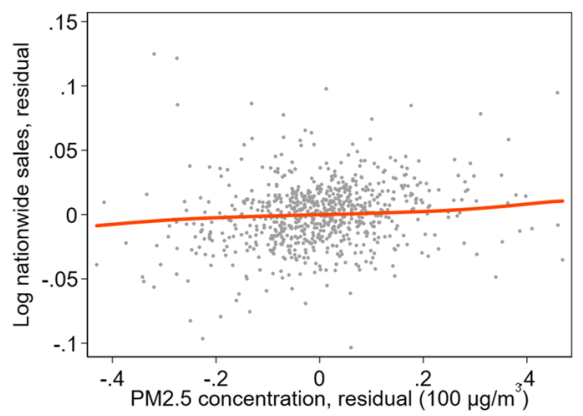

(d) Double Color lottery sales

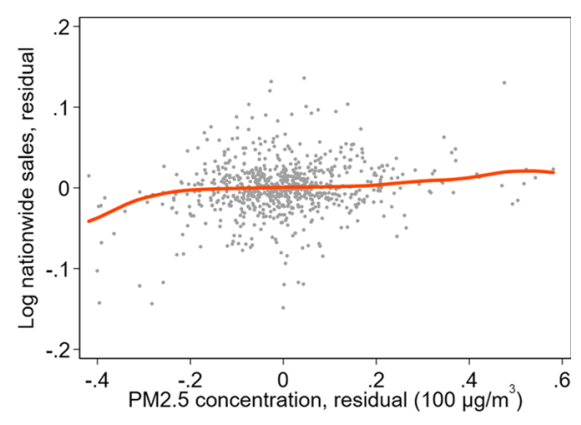

(f) Big Lotto lottery sales

Fig. 5 Residuals of log nationwide sales, for the six largest number lotteries, against residuals of nationally aggregated PM2.5 on the day of the draw, after partialing out time fixed effects (month-by-year, dayof-week, and public holiday) and weather (quadratics in temperature and dew point depression) from each time series. An observation is a day (draw) in the period January 2013 to December 2017. The fixed-prize lotteries in panels a to c have draws every day, so the time series are daily. The variable-prize lotteries in panels d to $f$ have three draws per week, so the frequency of the time series are thrice weekly. Environmental variables are aggregated across provinces as described in Table 1. For better visualization, the panels omit a few outlying residuals and show locally weighted polynomial fits 
Table 6 External validity: Daily 3D and 4D lottery sales and PM2.5 in Taiwan

\begin{tabular}{|c|c|c|c|c|}
\hline \multirow{3}{*}{$\begin{array}{l}\text { The dependent variable is the } \\
\text { log of } 3 \mathrm{D} \text { or } 4 \mathrm{D} \text { lottery sales. } \\
\text { All estimates are in log points. }\end{array}$} & \multicolumn{2}{|l|}{ OLS } & \multicolumn{2}{|l|}{ 2SLS } \\
\hline & $3 \mathrm{D}$ & $4 \mathrm{D}$ & $3 \mathrm{D}$ & $4 \mathrm{D}$ \\
\hline & (1) & (2) & (3) & (4) \\
\hline \multirow[t]{2}{*}{$\operatorname{PM} 2.5\left(\times 10^{2} \mu \mathrm{g} / \mathrm{m}^{3}\right)$} & $0.323 * * *$ & $0.283 * * *$ & $1.455^{* *}$ & $1.203 * * *$ \\
\hline & $(0.082)$ & $(0.059)$ & $(0.569)$ & $(0.437)$ \\
\hline \multirow[t]{2}{*}{ PM2.5 squared } & $-0.449 * * *$ & $-0.354 * * *$ & $-2.152 * *$ & $-1.701 * *$ \\
\hline & $(0.128)$ & $(0.092)$ & $(0.897)$ & $(0.691)$ \\
\hline \multirow[t]{2}{*}{ Effect of 10 to $50 \mu \mathrm{g} / \mathrm{m}^{3}$} & $0.021 * *$ & $0.028 * * *$ & $0.066^{* *}$ & $0.073 * * *$ \\
\hline & $(0.010)$ & $(0.006)$ & $(0.032)$ & $(0.022)$ \\
\hline Number of observations & 1,515 & 1,515 & 1,503 & 1,503 \\
\hline Number of regressors & 74 & 74 & 73 & 73 \\
\hline R-squared & 0.705 & 0.765 & & \\
\hline First-stage F-statistic & & & 6.717 & 6.717 \\
\hline
\end{tabular}

The table shows estimates for 2 OLS regressions (left) and 2 2SLS regressions (right) of log daily Taiwanese $3 \mathrm{D}$ or $4 \mathrm{D}$ lottery sales on daytime PM2.5. An observation is a day in the period January 2014 to December 2018. All models include complete sets of bins for ambient temperature and dew point temperature depression, each of width $5^{\circ} \mathrm{C}$, day-of-week FE, public holiday FE, and month-by-year FE. 2SLS instruments for measured PM2.5 (and its square), $P$, using the fitted value for regime-induced PM2.5 (and its square), $\hat{P}$. HAC-robust standard errors are shown in parentheses. ${ }^{* *}$ Significant at $1 \%,{ }^{* *}$ at $5 \%$, ${ }^{*}$ at $10 \%$

tend to be larger, particularly under the 2SLS identifying assumption, evidence based on Taiwanese daily time series is consistent with our results using the province-day sample for mainland China. We note that some presence of online sales in Taiwan (Taiwanlottery.com.tw, 2019) can, by diminishing the potential role of outdoor avoidance in reducing lottery sales, explain the larger PM2.5 impact compared to what we find in mainland China.

\subsubsection{Heterogeneity}

We return to the province-day sample for 3D lottery sales in China. We cautiously explore whether the relationship between haze-induced adversity and lottery demand exhibits heterogeneity along some margins, for example, over the weekly cycle, with colder weather, and with short-run variation in the increasingly popular Shanghai Stock Exchange (SSE) composite index. To our baseline specifications in Table 2 (OLS and 2SLS), we include as regressors interaction terms between PM2.5 (and its square) and variables that might be related to the demand for hope. We control for the levels of these variables as well, allowing them to correlate with lottery demand directly. ${ }^{19}$ Table 7 reports on a subset of the specifications we have implemented.

\footnotetext{
${ }^{19}$ To implement 2SLS we interact these variables with instruments for PM2.5 and its square.
} 
Table 7 The impact of particle pollution on daily 3D lottery sales: Heterogeneity

\begin{tabular}{|c|c|c|c|c|c|}
\hline $\begin{array}{l}\text { PM2.5 and its square } \\
\text { interacted with specific } \\
\text { indicators (see caption). }\end{array}$ & $\begin{array}{l}\text { Poor Stock } \\
\text { Market vs. } \\
\text { other days }\end{array}$ & $\begin{array}{l}\text { Monday } \\
\text { vs. other } \\
\text { weekdays }\end{array}$ & $\begin{array}{l}\text { Monday } \\
\text { vs. } \\
\text { Saturday }\end{array}$ & $\begin{array}{l}\text { Cold } \\
\text { Day vs. } \\
\text { other }\end{array}$ & $\begin{array}{l}\text { No Heating } \\
\text { Subsidy \& } \\
\text { Cold Day }\end{array}$ \\
\hline OLS, estimates in log points & (1) & (2a) & $(2 b)$ & (3) & (4) \\
\hline Effect of 10 to $50 \mu \mathrm{g} / \mathrm{m}^{3}$ & $\begin{array}{l}0.010^{*} \\
(0.005)\end{array}$ & $\begin{array}{l}0.004 \\
(0.004)\end{array}$ & $\begin{array}{l}0.011 * \\
(0.006)\end{array}$ & $\begin{array}{l}-0.005 \\
(0.004)\end{array}$ & $\begin{array}{l}0.019 \\
(0.015)\end{array}$ \\
\hline Effect of 10 to $100 \mu \mathrm{g} / \mathrm{m}^{3}$ & $\begin{array}{l}0.021 * * \\
(0.010)\end{array}$ & $\begin{array}{l}0.008 \\
(0.008)\end{array}$ & $\begin{array}{l}0.022 * \\
(0.012)\end{array}$ & $\begin{array}{l}-0.010 \\
(0.008)\end{array}$ & $\begin{array}{l}0.036 \\
(0.030)\end{array}$ \\
\hline Effect of 10 to $150 \mu \mathrm{g} / \mathrm{m}^{3}$ & $\begin{array}{l}0.031 * * \\
(0.014)\end{array}$ & $\begin{array}{l}0.012 \\
(0.011)\end{array}$ & $\begin{array}{l}0.028 * \\
(0.016)\end{array}$ & $\begin{array}{l}-0.014 \\
(0.010)\end{array}$ & $\begin{array}{l}0.047 \\
(0.039)\end{array}$ \\
\hline Effect of 10 to $200 \mu \mathrm{g} / \mathrm{m}^{3}$ & $\begin{array}{l}0.041 * * \\
(0.017)\end{array}$ & $\begin{array}{l}0.015 \\
(0.014)\end{array}$ & $\begin{array}{l}0.032 * \\
(0.018)\end{array}$ & $\begin{array}{l}-0.018 * \\
(0.011)\end{array}$ & $\begin{array}{l}0.051 \\
(0.045)\end{array}$ \\
\hline 2SLS, estimates in log points & (5) & (6a) & $(6 b)$ & (7) & (8) \\
\hline Effect of 10 to $50 \mu \mathrm{g} / \mathrm{m}^{3}$ & $\begin{array}{l}0.018^{* * *} \\
(0.008)\end{array}$ & $\begin{array}{l}0.004 \\
(0.006)\end{array}$ & $\begin{array}{l}0.024 * * * \\
(0.009)\end{array}$ & $\begin{array}{l}-0.005 \\
(0.007)\end{array}$ & $\begin{array}{l}0.014 \\
(0.033)\end{array}$ \\
\hline Effect of 10 to $100 \mu \mathrm{g} / \mathrm{m}^{3}$ & $\begin{array}{l}0.034 * * \\
(0.014)\end{array}$ & $\begin{array}{l}0.008 \\
(0.012)\end{array}$ & $\begin{array}{l}0.038 * * \\
(0.016)\end{array}$ & $\begin{array}{l}-0.011 \\
(0.012)\end{array}$ & $\begin{array}{l}0.027 \\
(0.062)\end{array}$ \\
\hline Effect of 10 to $150 \mu \mathrm{g} / \mathrm{m}^{3}$ & $\begin{array}{l}0.044 * * \\
(0.018)\end{array}$ & $\begin{array}{l}0.010 \\
(0.015)\end{array}$ & $\begin{array}{l}0.036 * \\
(0.020)\end{array}$ & $\begin{array}{l}-0.017 \\
(0.015)\end{array}$ & $\begin{array}{l}0.034 \\
(0.079)\end{array}$ \\
\hline Effect of 10 to $200 \mu \mathrm{g} / \mathrm{m}^{3}$ & $\begin{array}{l}0.048 * * \\
(0.022)\end{array}$ & $\begin{array}{l}0.011 \\
(0.018)\end{array}$ & $\begin{array}{l}0.017 \\
(0.024)\end{array}$ & $\begin{array}{l}-0.023 \\
(0.015)\end{array}$ & $\begin{array}{l}0.036 \\
(0.083)\end{array}$ \\
\hline
\end{tabular}

Notes: The table shows estimates for 4 OLS regressions (top) and 4 2SLS regressions (bottom) of log daily 3D lottery sales on daytime PM2.5. An observation is a province by day (2013 to $2017, N=36,279$ in column 1 and $N=56,270$ otherwise). Other than where noted, models follow specifications 1 and 5 (OLS and 2SLS) of Table 2. We report the additional effect of PM2.5 shifts (e.g., 10 to $50 \mu \mathrm{g} / \mathrm{m}^{3}$ ) for specific interactions, e.g., Monday (interacted with PM2.5 and PM2.5 squared) vs. other weekdays. From left to right: $(1,5)$ We add an interaction between PM2.5 (also PM2.5 squared, hereafter) and an indicator for Poor Stock Market (=1 if the one-day return in the Shanghai Stock Exchange on the previous day is in the bottom $10 \%$ of the sample). $(2,6)$ We add interactions between PM2.5 and indicators for Monday, Saturday, and Sunday/public holiday. $(3,7)$ We add an interaction between PM2.5 and an indicator for Cold Day ( $=1$ if the temperature is in the bottom $10 \%$ of the sample). $(4,8)$ To $(3,7)$ we add an indicator for province without subsidized heating, its interaction with Cold Day, and No Heating Subsidy and Cold Day indicators' (separate and joint, i.e., triple) interactions with PM2.5. ${ }^{* * *}$ Significant at $1 \%,{ }^{* *}$ at $5 \%$, ${ }^{*}$ at $10 \%$

We first allow the economic and ambient environments to interact. As motivation, recall that Mikesell (1994) finds that US state lottery sales increase with state-level unemployment, suggesting that lottery demand rises when the economic environment deteriorates. Kumar (2009) documents that lottery expenditure is positively correlated with investment in lottery-type stocks, and that the demand for lotterytype stocks increases during economic downturns. It is plausible that stock market performance (a variable that moves daily) may correlate with lottery demand, and the participation rate in China's stock market is already quite high, e.g., 138 million Chinese owned stocks in 2018 (xinhuanet.com, 2018a). 
Columns 1 and 5 consider short-run stock market performance. A sharp fall in the stock market can be adversely perceived by individuals and potentially affect their hope attitudes and demand for lotteries. We generate a binary indicator that equals one if the one-day return in the Shanghai Stock Exchange on the previous day is in the bottom $10 \%$ of the distribution of one-day returns over the study period. The estimation sample thus excludes Sunday and Monday as there is no trading on Saturday and Sunday. As explained, we interact PM2.5 covariates with the Poor Stock Market indicator.

We find that the positive relationship between a day's lottery sales and PM2.5 grows stronger when the stock market performed badly the day before, that is, when high-frequency economic adversity and environmental adversity interact. We also explored interactions between PM2.5 and five-day or seven-day returns, obtaining similar associations. One possible interpretation is that when "bad news" interact, such as haze and a poor stock market, the desire for "good news" to look forward to may grow stronger. While finding this association interesting, we caution that both short-run stock market performance and lottery demand may be responding to wider economic variables.

Research suggests that daily returns in the US stock market may vary systematically with day of the week (Birru, 2018). We consider whether the effect of PM2.5 on lottery demand differs by type of day. To our baseline specifications we include interactions between PM2.5 and separate indicators for Monday, Saturdays and Sundays/public holidays (we have explored other specifications). Columns 2 and 6 show that the PM2.5 effect is not significantly heterogeneous over the different weekdays and is perhaps stronger on Saturday.

We consider the interaction between PM2.5 and cold weather. We generate an indicator for cold days, defined as temperature in the bottom $10 \%$ of the provinceday sample. Columns 3 and 7 report that the effect of PM2.5 on lottery demand is not significantly different on cold vs. normal days. If anything, the effect of PM2.5 on lottery demand is somewhat lower on cold days, which is consistent with avoidance of the cold outdoors (less gamblers visiting street-based lottery outlets irrespective of haze).

It is possible that individuals stay inside with space-heating on cold days. Studies have documented that, unlike their northern counterparts, cities south of the Huai river and Qin mountains do not enjoy subsidized heating, despite winter temperatures occasionally falling below $0^{\circ} \mathrm{C}$ (e.g., Chen et al. 2013; Chu et al. 2018). We generate an indicator for the absence of subsidized heating, equal to one if the province's capital city lies south of the Huai-Qin boundary. To check whether the impact of haze on lottery demand depends on temperature when it is difficult for households to seek comfort indoors, to our baseline specification we add a triple interaction between the cold-day indicator, the no-subsidized-heating indicator, and PM2.5. Columns 4 and 8 suggest that the impact of PM2.5 on lottery demand may be stronger in cold vs. non-cold days in cities where heating is not subsidized, but this difference is not statistically significant. 


\section{Discussion}

Drawing on both laboratory and field observations, the economics and psychology literatures reveal a tendency for individuals to display longshot preference, i.e., risk affinity towards small chances of sizable gains, while simultaneously exhibiting aversion to risk involving moderate chances of winning (Kahneman \& Tversky, 1979; Chark et al., 2020). Theoretical models offer preferential foundations for the observed concurrence of longshot preference behavior revealed in lottery purchases and pervasive risk aversion evident in capital markets (see, e.g., Quiggin 1991; Chew $\&$ Tan 2005). The literature has also developed models of preference over the timing of uncertainty resolution —or hope attitude-being distinct from attitude towards risk (Kreps \& Porteus, 1978; Chew \& Epstein, 1989).

Empirical evidence supports the notion that individuals tend to exhibit hopefulness when facing longshots, even choosing to delay their resolution (Chew \& Ho, 1994). Lotteries have been described as "selling hope" (Clotfelter \& Cook, 1989), and "are perhaps best understood in terms of the anticipatory fantasies and hopeful excitement that they permit" (Lovallo \& Kahneman, 2000). In this regard, one may draw a further distinction between hope underpinned by optimism as in probability overweighting versus hope in terms of savoring the prospect of a positive resolution of uncertainty in the future.

An empirical literature points to increased demand for hope products, including lotteries and lottery-type stocks, at times of economic and environmental adversity (e.g., Mikesell 1994; Kumar 2009; Li et al. 2011; Olason et al. 2017). ${ }^{20}$ To some, candles are symbols of hope, and the press commonly shows footage of crowds holding lit candles in the aftermath of adverse events-whether natural or manmade, for example, an earthquake, a mass shooting, or the death of a celebrity (such as the Princess of Wales killed in a car accident in 1997). Besides an increase in hope, the literature finds that adversity may also induce less optimism and thus more pessimism in people (Kivimäki et al., 2005).

The empirical relationship we present adds to these findings across disciplines. Our design and robustness across data sources heightens our confidence that the result is not a statistical artifact or due to confounding factors. We study adversity in the form of pollution shocks that vary widely and visibly over time and space in a country of land area comparable to the US. The purchase of lottery tickets is widespread across Chinese households, not confined to problem or pathological gamblers. ${ }^{21}$ Morning pollution has a larger impact than pollution in the afternoon, when the time to uncertainty resolution is shorter. We estimate a similarly large and statis-

\footnotetext{
${ }^{20}$ In this context, 2020 has been marked by significant growth in non-institutional (retail or "day") traders in lottery-type stocks and rising equity prices in conjunction with a once-in-a-century pandemic.

${ }^{21}$ By way of identification, we specify up to month-by-year-by-province intercepts to control for timevarying omitted determinants of lottery demand-particularly local economic activity - thus relying on co-variation in lottery demand and pollution within month-of-sample and province. To allow for even higher frequency shocks to economic activity, from one day to the next, we condition on pollution variation induced by local atmospheric regime shifts, to which economic activity is unlikely to respond.
} 
tically significant relationship using data from different state lottery providers - two separate authorities for mainland China, yet another for Taiwan.

We obtain a positive relationship despite possible avoidance behavior (Chu et al., 2020). Were routine haze to induce some individuals to stay at home, and given the limited opportunities for online lottery purchase directly from home, we conjecture that pollution's impact on lottery demand would be higher still in the absence of avoidance or the presence of online sales. Indeed, this is consistent with our estimates for Taiwan.

Recent papers point to a positive association between air pollution and risk aversion based on overall stock market data (Levy \& Yagil, 2011; Li \& Peng, 2016; Li et al., 2017). This is in line with the direct finding of increased aversion to evenchance risk in (Chew et al., 2021), because financial investments generally involve deliberation over more-or-less evenly distributed risks with positive returns in which risk aversion plays a key role. In contrast, lotteries concern skewed prospects with negative actuarial values, typically involving delayed resolutions, in which a more impulsive motive such as hope may be at play. In this regard, there also are lotterytype stocks (Kumar, 2009) which exhibit positive skewness and excess kurtosis with poorer returns relative to the overall market.

Future work using observational or experimental evidence can verify whether adversity shocks-including pollution, snow, stock markets, conflict, terrorism, pandemics - shift the demand for lotteries in terms of the timing of uncertainty resolution, or induce substitution across lottery and investment products. Lottery sales data at a granular spatial level such as neighborhood or city may be available and combined with demographic data such as income. Spain's two-century-old multibillion Christmas lottery, with advance sales taking place as early as July, points to the prevalence of consumption of hope. Our adversity-hope hypothesis predicts that, all else equal, such lottery sales would grow with, for example, terrorist-group ETA bombings in time and space. ${ }^{22}$ Individual-level data can further allow one to assess whether adversity induces a compositional change in the demand for lottery and investment products.

In the context of a theoretical literature that models hope and optimism as drivers of lottery demand, we interpret our results for pollution-induced daily lottery sales in China through the lens of the adversity-hope hypothesis. In the face of adversity, an increase in lottery demand is plausibly due to hope rather than to optimism (feeling lucky or confident). An increase in optimism when confronted with air pollution would be hard to square with studies that find that haze reduces subjective wellbeing (Zhang et al., 2017; Zheng et al., 2019). By the adversity-hope hypothesis, hazy and smoggy days shift preferences over the timing of uncertainty resolution. As

\footnotetext{
${ }^{22}$ (Bagues \& Esteve-Volart, 2016) and (Kent \& Martinez-Marquina, 2020) examine income shocks from Spain's Christmas lottery. As another example of spatial data, (Guryan \& Kearney, 2010) use lottery sales at the store level available for Texas (across 1,386 cities and 3,660 nine-digit zip codes). Much of the economic literature studying lottery data uses lottery wins as exogenous income shocks (e.g., Imbens et al. 2001; Lindahl 2005; Hankins et al. 2011; Kuhn et al. 2011), rather than a variable to be explained as is our case (lottery demand). In principle, these empirical settings provide further opportunities to test the adversity-hope hypothesis.
} 
the environment around them grows more severe, individuals may seek "good news" with greater fervor. Says an Arab proverb (noted in CH94), "there is fear in every hope, and hope in every fear."

Supplementary Information The online version contains supplementary material available at http://dx.doi.org/10.1007/s11166-021-09353-w.

Acknowledgments The authors acknowledge support from China's National Science Foundation key project no. 72033006 (S.H.C.) and Singapore's Ministry of Education Academic Research Fund Tier 1 grant R-122-000-250-115 (A.S. and H.L.).

Funding Open Access funding enabled and organized by Projekt DEAL.

Data and code availability Data and code used in this study are available on Dataverse https://doi.org/10.7910/DVN/A0WZ9D. All data used in this study are from public sources.

\section{Declarations}

Conflict of Interests The authors declare no competing financial or nonfinancial interests.

Open Access This article is licensed under a Creative Commons Attribution 4.0 International License, which permits use, sharing, adaptation, distribution and reproduction in any medium or format, as long as you give appropriate credit to the original author(s) and the source, provide a link to the Creative Commons licence, and indicate if changes were made. The images or other third party material in this article are included in the article's Creative Commons licence, unless indicated otherwise in a credit line to the material. If material is not included in the article's Creative Commons licence and your intended use is not permitted by statutory regulation or exceeds the permitted use, you will need to obtain permission directly from the copyright holder. To view a copy of this licence, visit http://creativecommons.org/licenses/by/4. $0 /$.

\section{References}

AGTech (2018). The People's Republic of China (PRC): A large but still under-penetrated lottery market. www.agtech.com/html/lottery-reg/index-en.html, Accessed on June 17, 2018.

Anderson, M. L. (2020). As the wind blows: the effects of long-term exposure to air pollution on mortality. Journal of the European Economic Association, 18(4), 1886-1927.

Angrist, J. D., \& Krueger, A. B. (2001). Instrumental variables and the search for identification: from supply and demand to natural experiments. Journal of Economic Perspectives, 15(4), 69-85.

Archsmith, J., Heyes, A., \& Saberian, S. (2018). Air quality and error quantity: Pollution and performance in a high-skilled, quality-focused occupation. Journal of the Association of Environmental and Resource Economists, 5(4), 827-863.

Bagues, M., \& Esteve-Volart, B. (2016). Politicians' luck of the draw: Evidence from the Spanish Christmas lottery. Journal of Political Economy, 124(5), 1269-1294.

Betting Guide (2018). Gambling law of Chinese Mainland. https://www.onlinebetting.com/legal/china/, Accessed on June 17, 2018.

Birru, J. (2018). Day of the week and the cross-section of returns. Journal of Financial Economics, 130(1), $182-214$.

Chark, R., Chew, S. H., \& Zhong, S. (2020). Individual preference for longshots. Journal of the European Economic Association, 18(2), 1009-1039.

Chen, Y., Ebenstein, A., Greenstone, M., \& Li, H. (2013). Evidence on the impact of sustained exposure to air pollution on life expectancy from China's Huai River policy. Proceedings of the National Academy of Sciences, 110(32), 12936-12941. 
Chew, S. H. (1983). A generalization of the quasilinear mean with applications to the measurement of income inequality and decision theory resolving the Allais paradox. Econometrica, 51(4), 1065-1092.

Chew, S. H., \& Epstein, L. G. (1989). The structure of preferences and attitudes towards the timing of the resolution of uncertainty. International Economic Review, 30(1), 103-117.

Chew, S. H., \& Ho, J. L. (1994). Hope: an empirical study of attitude toward the timing of uncertainty resolution. Journal of Risk and Uncertainty, 8(3), 267-288.

Chew, S. H., Huang, W., \& Li, X. (2021). Does haze cloud decision making? a natural laboratory experiment. Journal of Economic Behavior \& Organization, 182, 132-161.

Chew, S. H., \& Tan, G. (2005). The market for sweepstakes. Review of Economic Studies, 72(4), 10091029.

Chu, J., Liu, H., \& Png, I.P.L. (2018). Nonlabor income and age at marriage: Evidence from China's Heating Policy. Demography, 55(6), 2345-2370.

Chu, J., Liu, H., \& Salvo, A. (2020). Air pollution as a determinant of food delivery and related plastic waste. Nature Human Behaviour October, 19, 1-14.

Clotfelter, C. T., \& Cook, P. J. (1989). Selling Hope: State Lotteries in America. Cambridge: Harvard University Press.

cwl.gov.cn (2017). China's Welfare Lottery. www.cwl.gov.cn/c/2017-11-15/418907.shtml, Accessed on June 17, 2018.

Dominici, F., Peng, R. D., Barr, C. D., \& Bell, M.L. (2010). Protecting human health from air pollution: Shifting from a single-pollutant to a multipollutant approach. Epidemiology, 21(2), 187-194.

Ebenstein, A., Lavy, V., \& Roth, S. (2016). The long-run economic consequences of high-stakes examinations: Evidence from transitory variation in pollution. American Economic Journal: Applied Economics, 8(4), 36-65.

Ghanem, D., \& Zhang, J. (2014). Effortless perfection: Do Chinese cities manipulate air pollution data? Journal of Environmental Economics and Management, 68(2), 203-225.

Graff Zivin, J., Liu, T., Song, Y., Tang, Q., \& Zhang, P. (2020). The unintended impacts of agricultural fires: Human capital in China. Journal of Development Economics, 147, 102560.

Guryan, J., \& Kearney, M. S. (2010). Is lottery gambling addictive?. American Economic Journal: Economic Policy, 2(3), 90-110.

Ham, J. C., Zweig, J. S., \& Avol, E. (2014). Pollution, test scores and the distribution of academic achievement: Evidence from California schools, 2002-2008. Unpublished manuscript.

Hankins, S., Hoekstra, M., \& Skiba, P.M. (2011). The ticket to easy street? the financial consequences of winning the lottery. Review of Economics and Statistics, 93(3), 961-969.

He, J., Gouveia, N., \& Salvo, A. (2019). External effects of diesel trucks circulating inside the Sao Paulo megacity. Journal of the European Economic Association, 17(3), 1-43.

He, J., Liu, H., \& Salvo, A. (2019). Severe air pollution and labor productivity:, Evidence from industrial towns in China. American Economic Journal: Applied Economics, 11(1), 1-31.

He, X., Luo, J., \& Zhang, J. (2017). When airpocalypse met blockbusters: The impact of air pollution on the box office. Unpublished manuscript.

Herrnstadt, E., Heyes, A., Muehlegger, E., \& Saberian, S. (2019). Air pollution as a cause of violent crime. Unpublished manuscript.

Herrnstadt, E., Heyes, A., Muehlegger, E., \& Saberian, S. (2021). Air pollution and criminal activity: Microgeographic evidence from Chicago. American Economic Journal: Applied Economics Forthcoming.

Imbens, G. W., Rubin, D. B., \& Sacerdote, B.I. (2001). Estimating the effect of unearned income on labor supply, earnings, savings, and consumption: Evidence from a sample of lottery players. American Economic Review, 91(4), 778-794.

Isen, A., Rossin-Slater, M., \& Walker, W.R. (2017a). Every breath you take, every dollar you'll make: The long-term consequences of the Clean Air Act of 1970. Journal of Political Economy, 125(3), 848-902.

Isen, A., Rossin-Slater, M., \& Walker, W.R. (2017b). Relationship between season of birth, temperature exposure, and later life wellbeing. Proceedings of the National Academy of Sciences, 114(51), 1344713452.

Isidore, C. (2017). Why billions of dollars go unclaimed in lottery prizes. New York Times, August 24.

Kahneman, D., \& Tversky, A. (1979). Prospect theory: an analysis of decision under risk. Econometrica, 47(2), 263-91.

Kent, C., \& Martinez-Marquina, A. (2020). When a town wins the lottery: Evidence from Spain. Unpublished manuscript. 
Kivimäki, M., Vahtera, J., Elovainio, M., Helenius, H., Singh-Manoux, A., \& Pentti, J. (2005). Optimism and pessimism as predictors of change in health after death or onset of severe illness in family. Health Psychology, 24(4), 413-421.

Kreps, D. M., \& Porteus, E. L. (1978). Temporal resolution of uncertainty and dynamic choice theory. Econometrica, 46(1), 185-200.

Kuhn, P., Kooreman, P., Soetevent, A. R., \& Kapteyn, A. (2011). The effects of lottery prizes on winners and their neighbors: Evidence from the Dutch Postcode Lottery. American Economic Review, 101(5), 2226-2247.

Kumar, A. (2009). Who gambles in the stock market? Journal of Finance, 64(4), 1889-1933.

Lelieveld, J., Evans, J. S., Fnais, M., Giannadaki, D., \& Pozzer, A. (2015). The contribution of outdoor air pollution sources to premature mortality on a global scale. Nature, 525(7569), 367-371.

Levinson, A. (2012). Valuing public goods using happiness data: the case of air quality. Journal of Public Economics, 96(9), 869-880.

Levy, T., \& Yagil, J. (2011). Air pollution and stock returns in the US. Journal of Economic Psychology, 32(3), 374-383.

Li, J., Massa, M., Zhang, H., \& Zhang, J. (2017). Behavioral bias in haze: Evidence from air pollution and the disposition effect in China. Unpublished manuscript.

Li, J.-Z., Li, S., Wang, W.-Z., Rao, L.-L., \& Liu, H. (2011). Are people always more risk averse after disasters? Surveys after a heavy snow-hit and a major earthquake in China in 2008. Applied Cognitive Psychology, 25(1), 104-111.

Li, Q., \& Peng, C. H. (2016). The stock market effect of air pollution: Evidence from China. Applied Economics, 48(36), 3442-3461.

Lindahl, M. (2005). Estimating the effect of income on health and mortality using lottery prizes as an exogenous source of variation in income. Journal of Human Resources, 40(1), 144-168.

Liu, H., \& Salvo, A. (2018). Severe air pollution and child absences when schools and parents respond. Journal of Environmental Economics and Management, 92, 300-330.

Lopes, L. L. (1987). Between hope and fear: the psychology of risk. Advances in Experimental Social Psychology, 20, 255-295.

Lovallo, D., \& Kahneman, D. (2000). Living with uncertainty: Attractiveness and resolution timing. Journal of Behavioral Decision Making, 13(2), 179-190.

Lu, J. G. (2020). Air pollution: a systematic review of its psychological, economic, and social effects. Current Opinion in Psychology, 32, 52-65.

Lu, J. G., Lee, J. J., Gino, F., \& Galinsky, A.D. (2018). Polluted morality: Air pollution predicts criminal activity and unethical behavior. Psychological Science, 29(3), 340-355.

Marlier, M. E., Jina, A. S., Kinney, P. L., \& DeFries, R.S. (2016). Extreme air pollution in global megacities. Current Climate Change Reports, 2(1), 15-27.

Meyer, S., \& Pagel, M. (2017). Fresh air eases work - the effect of air quality on individual investor activity. NBER Working Paper No. 24048.

Mikesell, J. L. (1994). State lottery sales and economic activity. National Tax Journal, 47(1), 165-171.

Ministry of Finance (2017). December 2017 lottery sales in People's Republic of China. http://zhs.mof. gov.cn/zhengwuxinxi/zonghexinxi/201801/t20180123_2799468.html, Accessed on October 9, 2018.

North, C. S., Pfefferbaum, B., Narayanan, P., Thielman, S., McCoy, G., Dumont, C., Kawasaki, A., Ryosho, N., Kim, Y. S., \& Spitznagel, E.L. (2005). Comparison of post-disaster psychiatric disorders after terrorist bombings in Nairobi and Oklahoma City. British Journal of Psychiatry, 186(6), 487-493.

Olason, D. T., Hayer, T., Meyer, G., \& Brosowski, T. (2017). Economic recession affects gambling participation but not problematic gambling: Results from a population-based follow-up study. Frontiers in Psychology, 8, 1247.

Price, D. I., \& Novak, E. S. (1999). The tax incidence of three Texas lottery games: Regressivity, race, and education. National Tax Journal, 52(4), 741-751.

Quiggin, J. (1991). On the optimal design of lotteries. Economica, 58(229), 1-16.

Seibert, P., Beyrich, F., Gryning, S.-E., Joffre, S., Rasmussen, A., \& Tercier, P. (2000). Review and intercomparison of operational methods for the determination of the mixing height. Atmospheric Environment, 34(7), 1001-1027.

Sibley, C. G., \& Bulbulia, J. (2012). Faith after an earthquake: A longitudinal study of religion and perceived health before and after the 2011 Christchurch New Zealand earthquake. PLOS ONE, 7(12), e49648. 
Taiwanlottery.com.tw (2019). Taiwan's Welfare Lottery. www.Taiwanlottery.com.tw/about/lottery.asp, Accessed on March 29, 2019.

Tang, G., Zhang, J., Zhu, X., Song, T., Münkel, C., Hu, B., Schäfer, K. J., Liu, Z., Zhang, J., Wang, L., Xin, J., Suppan, P., \& Wang, Y. (2016). Mixing layer height and its implications for air pollution over Beijing, China. Atmospheric Chemistry and Physics, 16, 2459-2475.

Watson, J. G. (2002). Visibility: Science and regulation. Journal of the Air \& Waste Management Association, 52(6), 628-713.

xinhuanet.com (2018a). 138 million investors on average hold stocks of 1.3 companies. http://www. xinhuanet.com/money/2018-05/08/c_129866753.htm. Accessed on March 4, 2019.

xinhuanet.com (2018b). Twelve departments' joint announcement on prohibiting online lottery sales. http://www.xinhuanet.com/tech/2018-08/22/c_1123306129.htm. Accessed on August 16, 2018.

Zezima, K. (2008). Sweet dreams in hard times add to lottery sales. New York Times, September 13.

Zhang, Q., Quan, J., Tie, X., Li, X., Liu, Q., Gao, Y., \& Zhao, D. (2015). Effects of meteorology and secondary particle formation on visibility during heavy haze events in Beijing, China. Science of the Total Environment, 502, 578-584.

Zhang, X., Chen, X., \& Zhang, X. (2018). The impact of exposure to air pollution on cognitive performance. Proceedings of the National Academy of Sciences, 115(37), 9193-9197.

Zhang, X., Zhang, X., \& Chen, X. (2017). Happiness in the air: How does a dirty sky affect mental health and subjective well-being? Journal of Environmental Economics and Management, 85, 81-94.

Zheng, S., Wang, J., Sun, C., Zhang, X., \& Kahn, M.E. (2019). Air pollution lowers Chinese urbanites' expressed happiness on social media. Nature Human Behaviour, 3, 237-243.

Publisher's note Springer Nature remains neutral with regard to jurisdictional claims in published maps and institutional affiliations.

\section{Affiliations}

\section{Soo Hong Chew ${ }^{1,2} \cdot$ Haoming Liu ${ }^{2,3} \cdot$ Alberto Salvo $^{2}$}

Soo Hong Chew

chew.soohong@gmail.com

Alberto Salvo

albertosalvo@nus.edu.sg

1 China Center for Behavioral Economics and Finance, Southwestern University of Finance and Economics, 555 Liutai Avenue, Wenjiang District, Chengdu, Sichuan, 611130, People's Republic of China

2 Department of Economics, National University of Singapore, 1 Arts Link, Singapore, 117570, Singapore

3 IZA Institute of Labor Economics, Schaumburg-Lippe-Strasse 5-9, 53113, Bonn, Germany 